\title{
Sistema aquífero Alter do Chão a oeste da cidade de Manaus (AM): processos hidrogeoquímicos, origem da salinidade e relações com aquíferos adjacentes
}

\author{
Alter do Chão aquifer system west of Manaus city, Amazonas State, Brazil: \\ hydrochemical processes, origin of salinity and relations with adjacent aquifers
}

Renato Cosme dos Santos Pita1, Gerson Cardoso da Silva Júnior ${ }^{1}$, Fátima Ferreira do Rosário², Márcio Luiz da Silva 'Departamento de Geologia, Instituto de Geociências, Universidade Federal do Rio de Janeiro - UFRJ, Avenida Athos da Silveira Ramos, 274, CCMN, Sala J0-05, CEP 21941-916, Rio de Janeiro, RJ, BR (renato@geologia.ufrj.br; gerson@acd.ufrj.br) ${ }^{2}$ Centro de Pesquisas Leopoldo Américo Miguez de Mello - CENPES, Rio de Janeiro, RJ, BR (fatimarosario@petrobras.com.br) ${ }^{3}$ Instituto Nacional de Pesquisas da Amazônia - INPA, Manaus, AM, BR (marciols@inpa.gov.br)

Recebido em 05 de julho de 2017; aceito em 02 de março de 2018

\begin{abstract}
Resumo
O aquífero associado à Formação Alter do Chão (FAC) — subsistema aquífero Alter do Chão (AAC) — é o mais conhecido da região amazônica. Estudos recentes indicam sua possível conexão com o subsistema aquífero cretáceo Tikuna, que possui continuidade por todas as bacias amazônicas, ambos integrando o grande Sistema Aquífero Amazônico (SAA). O objetivo do presente trabalho foi o aperfeiçoamento do modelo conceitual de funcionamento do AAC a oeste de Manaus. A metodologia incluiu medidas do nível d'água, de parâmetros físico-químicos in situ em poços e amostragem para análises químicas e isotópicas das águas subterrâneas. Realizou-se o levantamento das características geológicas e limites do aquífero, baseado em dados de poços de petróleo e de abastecimento de água existentes. Os resultados revelaram que as águas do AAC a oeste de Manaus possuem duas origens principais: 1) origem meteórica, pouco mineralizadas, situadas nas camadas aquíferas superiores, em um sistema livre, com recarga local; 2) origem remota, mais mineralizadas, com maior tempo de residência no aquífero, armazenadas nas camadas mais profundas em um sistema provavelmente confinado, originadas possivelmente em áreas de recarga do bordo oeste do SAA. As análises isotópicas calibradas sugerem uma idade média de 21.380 anos para águas subterrâneas mais mineralizadas e profundas dos municípios de Manacapuru e Careiro. Essa água é, provavelmente, resultado de uma mescla de águas mais antigas com águas de recarga mais recente. Por conta dessa diferenciação hidrogeoquímica, correlacionada com a geologia local, o AAC foi subdividido em uma porção superior, livre e menos mineralizada, e outra inferior, mais antiga e mineralizada, ambas misturadas a leste do Arco de Purus, com progressiva diluição pela chuva.
\end{abstract}

Palavras-chave: Aquífero Alter do Chão; Hidrogeologia; Hidrogeoquímica; Região Metropolitana de Manaus.

\begin{abstract}
The aquifer associated with the Alter do Chão Formation (ACF) - Alter do Chão Aquifer subsystem (ACA) - is the best known in the Amazon region. Recent studies have indicated its possible connection with the Cretaceous Tikuna Subsystem, which is continuous throughout the Amazon basins, both parts of the great Amazon Aquifer System (AAS). The aim of the article was to generate new insights on the ACA functioning, in the west of Manaus. The methodology included measurements of water level and in situ physical-chemical parameters in wells, along with groundwater sampling for chemical and isotopic analysis. Geological characteristics and aquifer boundaries were estimated with data from existing oil and water wells. Results show that ACA waters in western Manaus have two main origins: 1) meteoric origin, with poorly mineralized waters, situated in the upper aquifer layers in an unconfined system with local recharge; 2) remote origin, more mineralized, with longer residence time in the aquifer, stored in the deeper layers, probably in a confined system. Its origin is presumably in the recharging areas on the AAS western edge. Calibrated isotope analyzes suggest an average age of 21,380 years for more mineralized groundwater occurring in deeper wells from Manacapuru and Careiro municipalities. This water is probably the result of a mixture of older waters with more recent recharge waters. Due to the hydrogeochemical water variation, correlated with local geology, Alter do Chão Aquifer System was divided in an upper unconfined and less mineralized portion, and another older and mineralized lower portion, both mixed eastwards, with a progressive dilution by rainfall.
\end{abstract}

Keywords: Alter do Chão aquifer; Hydrogeology; Hidrogeochemistry; Manaus Metropolitan Area. 


\section{INTRODUÇÃO}

A Região Amazônica é uma das mais pluviosas do mundo e, por isso, a disponibilidade de água é muito grande, tanto superficial quanto subterraneamente. A maior reserva de água doce fluvial do planeta está na bacia hidrográfica do rio Amazonas, com cerca de $20 \%$ de toda a água dos rios da Terra. O Brasil tem uma disponibilidade hídrica de cerca de $14,7 \%$ de toda a água doce em estado líquido no mundo (FAO, 2003), sendo que $80 \%$ da água doce do país encontra-se na Região Amazônica.

Esse panorama pode levar a presumir que o abastecimento de água na Amazônia não é um problema, e que o recurso hídrico é abundante o suficiente para que não haja preocupação quanto a esse tema. Porém, isso não é a realidade na região. Apesar da grande disponibilidade de água superficial na Amazônia, nas proximidades dos agrupamentos urbanos, frequentemente esta é inapropriada para o consumo humano, por efeito de contaminação microbiológica ou pela ocorrência de parâmetros físico-químicos ou organolépticos fora dos limites permitidos ou desejáveis (Azevedo, 2006). A Região Metropolitana de Manaus (RMM) teve um acelerado crescimento econômico e demográfico nos últimos anos, que vem provocando forte pressão sobre o meio ambiente de forma geral, e em especial sobre os recursos hídricos.

Diante deste cenário, observa-se a crescente explotação de água subterrânea na Amazônia, por apresentar vantagens práticas e econômicas quanto a sua captação e dispensar tratamentos sofisticados por ser, em geral, de boa qualidade (Silva e Silva, 2007). Segundo Souza (2005), o Amazonas tem uma utilização de água subterrânea de $80 \mathrm{~m}^{3} \cdot \mathrm{hab}^{-1} \cdot \mathrm{ano}^{-1}$, sendo o estado que proporcionalmente mais utiliza este recurso no Brasil. O conhecimento sobre as características hidrogeológicas dos aquíferos da região é ainda reduzido. Também não há uma integração das informações hidrogeológicas locais e regionais. Isso dificulta o planejamento e a execução de programas de gestão integrada dos recursos hídricos nessa região (Souza et al., 2013).

O AAC é o manancial de maior importância para a Região Amazônica Oriental, sendo responsável por boa parte do abastecimento de importantes cidades como Manaus e Santarém, além de diversos municípios e povoados menores, onde ganha ainda mais relevância no abastecimento. A maior parte dos estudos hidrogeológicos concentra-se no AAC, porém apenas ao redor das maiores cidades (Souza, 2005; Silva e Bonotto, 2006; Silva e Silva, 2007; Aguiar, 2012). As demais áreas deste vasto sistema aquífero, longe das aglomerações humanas mais importantes, têm muito poucos estudos hidrogeológicos abrangentes.

Na Região Amazônica Ocidental, com a Formação Alter do Chão (FAC) em grandes profundidades, os aquíferos mais utilizados para o abastecimento são os das formações Içá e
Solimões, mais rasos e com águas geralmente de boa qualidade (Galvão et al., 2012; Souza et al., 2015). Porém, apresentam elevada vulnerabilidade natural à poluição, por serem freáticos e com nível de água muito raso.

Neste trabalho, buscou-se caracterizar a hidrogeologia e hidrogeoquímica do Sistema Aquífero Alter do Chão (AAC) no extremo ocidental de sua área de afloramento, onde ocorre uma importante interface entre o AAC e os aquíferos Içá e Solimões. Estes aquíferos passam a recobrir o AAC a oeste do município de Manacapuru. O estudo realizado na área pretende contribuir para o conhecimento hidrogeológico da região e o melhor entendimento do funcionamento regional deste sistema e de suas inter-relações com os demais aquíferos da Região Amazônica, a fim de proporcionar informações para a sua gestão e preservação.

\section{CARACTERIZAÇÃO DA ÁREA DE ESTUDO}

\section{Localização da área de estudo}

A área de estudo localiza-se na porção oeste de ocorrência da FAC em superfície, abrangendo os municípios de Iranduba e Manacapuru, pertencentes à RMM. A pesquisa também envolveu o estudo do AAC em profundidade, na porção da Bacia do Amazonas em que a FAC é recoberta pelas Formações Içá e Solimões (Figura 1). Foram analisadas amostras de água subterrânea nos municípios de Manaus, Iranduba, Manacapuru, Manaquiri e Careiro, além de um levantamento de dados já existentes em outros municípios localizados a oeste de Manaus, no estado do Amazonas.

\section{Geologia}

A área de estudo localiza-se na bacia sedimentar do Amazonas, que é uma bacia do tipo intracontinental, abrangendo uma área de cerca de $615.600 \mathrm{~km}^{2}$ (Figura 1). A bacia é delimitada pelo Arco de Purus a oeste, que a separa da Bacia do Solimões, pelo Arco de Gurupá a leste, que a separa da Bacia da Foz do Amazonas, Escudo das Guianas ao norte e Escudo Brasil Central ao sul (Caputo, 1984; Cunha et al., 2007). Seu arcabouço estratigráfico compreende duas megassequências deposicionais de primeira ordem, totalizando mais de 5 mil metros de preenchimento sedimentar. A primeira megassequência, de idade paleozoica, é composta de rochas sedimentares e tem grande volume de intrusões de diques e soleiras de diabásio, devido ao magmatismo Penatecaua, ocorrido durante o Triássico (Santos, 1978). A segunda, de idade mesozoica-cenozoica, é composta exclusivamente de rochas sedimentares e encerra a sedimentação na bacia, aflorando em discordância com a sequência anterior (ANP, 2015).

A segunda megassequência divide-se em duas sequências continentais: cretácea superior (FAC) e cenozoica 
(Formações Içá e Solimões), depositadas por sistemas fluviais e flúvio-lacustres, sendo reunidas no Grupo Javari (Silva et al., 2003). As rochas do Grupo Javari compõem o substrato geológico dos principais aquíferos da Região Amazônica, tendo grande importância quanto aos recursos hídricos. Seus aquíferos possuem grandes reservas, com águas em geral de boa qualidade e à pouca profundidade, sendo assim economicamente viáveis para a explotação e o abastecimento da população.

A FAC é constituída por argilas, siltes e areias interdigitadas, predominando os arenitos, geralmente tabulares, com estratificação cruzada acanalada e laminação cruzada. As rochas aflorantes são predominantemente vermelhas, mal selecionadas, feldspáticas e com conteúdo variável de micas (Silva, 2005). A Formação pode atingir até $1.250 \mathrm{~m}$ de espessura na Bacia do Amazonas, mas sua profundidade média é de cerca de $300 \mathrm{~m}$. É de difícil datação, pelo reduzido conteúdo fossilífero. Isto tem causado controvérsia e incerteza acerca da idade da Formação. Idades cretáceas e cenozoicas têm sido sugeridas pelos autores que a estudaram (Dino et al., 1999; Caputo, 2011; Price, 1960; Soares et al., 2016).

A Formação Solimões (FS), sobreposta à FAC em toda a Bacia do Solimões e em algumas partes da Bacia do Amazonas, consiste em uma sucessão de pelitos maciços e laminados, com linhitos intercalados e arenitos finos a

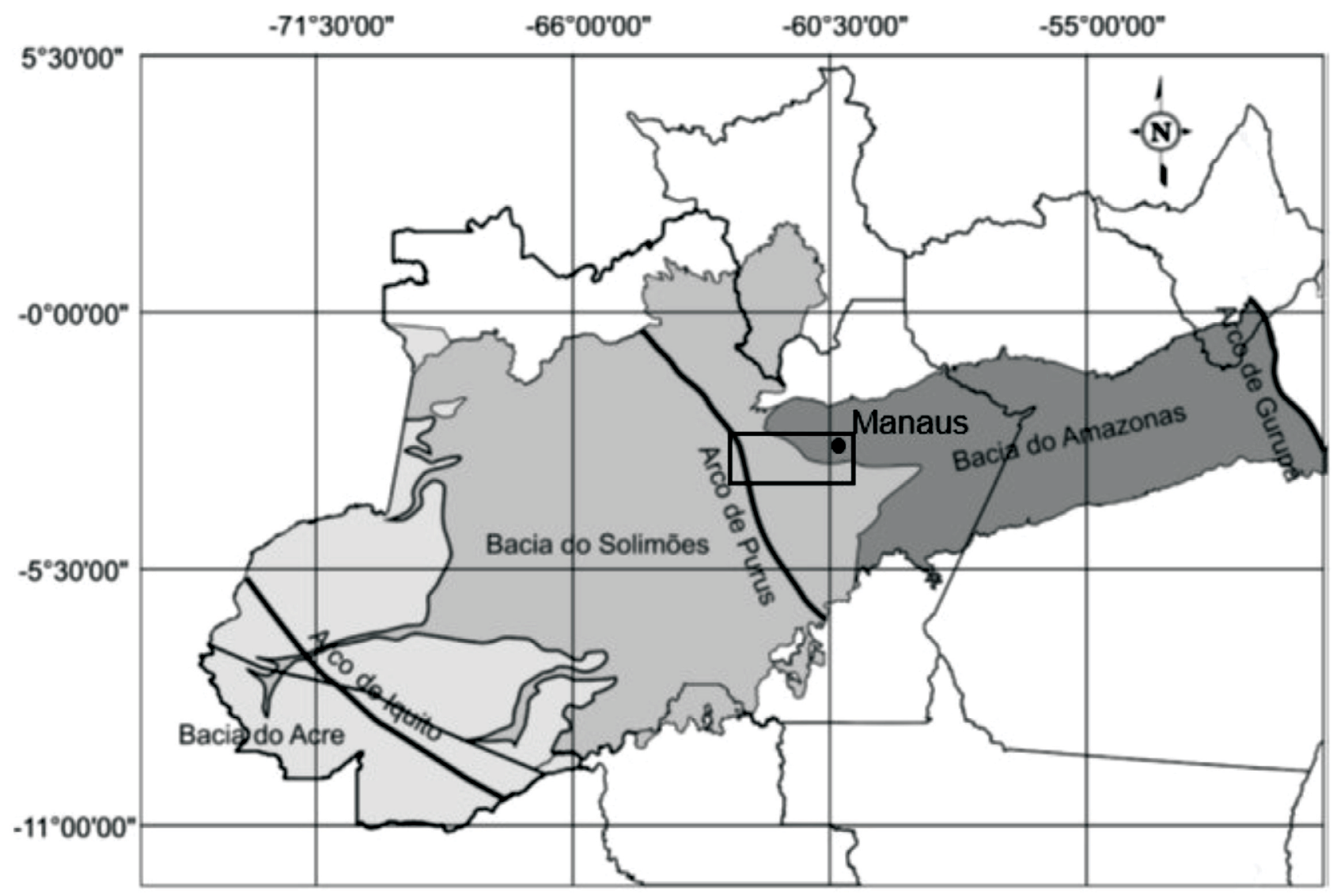

Formação Alter do Chão

Formação Içá

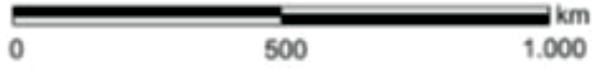

\section{Formaçẵo Solimões}

Fonte: Souza et al. (2013).

Figura 1. Localização de bacias sedimentares amazônicas, com os principais arcos estruturais que as limitam e extensão das formações aflorantes. Em destaque, a localização da área de estudo. 
grossos. Na base predominam as camadas argilosas maciças, ricas em fósseis. No topo, dominam os arenitos finos a grossos subangulares a subarredondados. Na Bacia do Amazonas, a FS ocorre somente no extremo oeste, nas proximidades do Arco de Purus, e é pouco espessa, enquanto na Bacia do Solimões atinge grandes espessuras e extensões (Souza et al., 2013).

A Formação Içá, mais nova na sequência estratigráfica, aflora em cerca de $205 \mathrm{mil} \mathrm{km}{ }^{2}$ na Bacia do Amazonas, exclusivamente na parte ocidental. Esta unidade é constituída de arenitos finos a médios e siltitos, localmente com conglomerados, estando sobreposta discordantemente à FS (Motta, 2008). Sua idade é considerada pliopleistocênica pela maioria dos autores (Rossetti et al., 2005; Silveira e Souza, 2015). Os sedimentos foram depositados em ambiente fluvial de oeste para leste. Souza et al. (2013) sugerem que essas formações sejam agrupadas nos estudos hidrogeológicos com a denominação "Içá-Solimões", pela dificuldade de determinar seus limites hidrogeológicos.

\section{Hidrogeologia e hidrogeoquímica}

A FAC é o principal domínio hidrogeológico na Bacia do Amazonas. Segundo a Agência Nacional de Águas (ANA, 2005), o AAC é do tipo livre e aflora na região centro-norte do Pará e leste do Amazonas, em uma área de 312.574 km². Muitas cidades dependem exclusivamente do aquífero para o abastecimento, denotando a sua importância para a população. Por isso, o AAC é o aquífero mais estudado da Região Amazônica, mas em geral as pesquisas são de abrangência apenas local.

Estudos recentes sugerem que este sistema pode ter conexões com outra unidade hidrogeológica regional, estendendo-se pelas bacias do Solimões e Acre, além de países vizinhos (Abreu et al., 2013; Rosário et al., 2016). Rosário et al. (2016) propõem a continuidade hidrogeológica das camadas cretáceas da FAC, em subsuperfície, com formações correspondentes de idade cretácea, nas bacias do Acre e bacias subandinas. Nelas, o sistema seria confinado por camadas de baixa permeabilidade mais recentes, com salinidades variáveis, chegando a salmouras. As camadas cretáceas aflorariam somente na Serra do Divisor, no Acre, e no cinturão de falhas subandinas, onde se configuraria uma área de recarga do sistema. Rosário (2011) propôs a denominação de Sistema Aquífero Tikuna (SAT) para tal sistema regional formado pelas camadas cretáceas desde os Andes até a Bacia do Solimões. Persistem ainda muitas lacunas de conhecimento, principalmente no que diz respeito ao funcionamento regional dos sistemas aquíferos amazônicos.

Os dados disponíveis indicam que o AAC encontra-se livre na maioria de sua extensão aflorante (Silva e Bonotto, 2006). A espessura do aquífero em Manaus varia em torno de $220 \mathrm{~m}$, sendo $175 \mathrm{~m}$ de espessura saturada. Estudo realizado na região de Santarém indica que essa espessura pode chegar a 430 m (Tancredi, 1996). Segundo Souza et al. (2013), a espessura da FAC pode alcançar até $1.250 \mathrm{~m}$ na Bacia do Amazonas.

Os parâmetros hidráulicos para os aquíferos associados à $\mathrm{FAC}$ são escassos. Estudo na região de Santarém (PA) indica condutividades hidráulicas $(\mathrm{K})$ entre $5,0 \times 10^{-5} \mathrm{e}$ $2,1 \times 10^{-4} \mathrm{~m} / \mathrm{s}$, transmissividade $(\mathrm{T})$ variando de $1,5 \times 10^{-3} \mathrm{a}$ $9,1 \times 10^{-3} \mathrm{~m}^{2} / \mathrm{s}$ e coeficiente de armazenamento (S) variando de 3,3 a $4,1 \times 10^{-4}$, com porosidade média de cerca de $20 \%$. Em Manaus, outro estudo aponta para K da ordem de $10^{-5} \mathrm{~m} / \mathrm{s}$ e T de $1,3 \times 10^{-3} \mathrm{~m}^{2} / \mathrm{s}$ (Gonçales e Miranda, 2014). Na região de Manaus parece haver uma tendência de fluxo das águas subterrâneas de nordeste para sudoeste, em direção ao rio Negro, o que aparentemente é uma característica local, por efeitos topográficos e de bombeamento, sendo restrita à porção mais rasa e livre do aquífero. Em Manaus, a oscilação sazonal dos níveis freáticos registrada chegou a 3,5 $\mathrm{m}$ (Aguiar, 2012), embora haja poucos registros dessa sazonalidade.

Predominam águas pouco mineralizadas na FAC, segundo os dados disponíveis, com sólidos totais dissolvidos (STD) inferiores a $100 \mathrm{mg} / \mathrm{L}, \mathrm{pH}$ ácido, variando entre 4,5 e 5,5, e condutividade elétrica (CE) entre 15,1 e $82,9 \mu \mathrm{S} / \mathrm{cm}$ (ANA, 2005; Aguiar, 2012). Esses dados são dos arredores de Manaus, indicando águas de infiltração rápida e baixos tempos de residência, em ambiente químico de circulação pobre (Silva, 2005). O potencial redox medido nas águas subterrâneas de Manaus, associadas à FAC, geralmente varia entre +93 e +256 mV (Silva e Bonotto, 2006). Podem ser geralmente consideradas como quimicamente aceitáveis para consumo (embora objetáveis quanto a certos parâmetros como o $\mathrm{pH}$ ), classificadas como bicarbonatadas e/ou cloretadas sódicas, sulfatadas ou potássicas. Águas cloretadas-potássicas ou sulfatadas-cloretadas potássicas também ocorrem. Por ser, em geral, um aquífero livre, com nível de água raso, e devido ao processo de explotação crescente, têm sido verificados nos últimos anos fortes indícios de contaminação de suas águas (Souza, 2005; Vasconcelos, 2006; Rocha e Horbe, 2006).

O AAC na região de estudo pode ter a qualidade das águas influenciada por formações sotopostas, principalmente a Formação Nova Olinda, composta de calcários e evaporitos. Falhas profundas podem facilitar o contato de águas enriquecidas em sais que circulam na Nova Olinda com as águas do AAC, em níveis profundos. Aguiar e Marmos (2010) citam poços públicos de abastecimento da cidade de Manacapuru, com pouco mais de $200 \mathrm{~m}$ de profundidade, que produzem "águas duras", com teores elevados de bicarbonatos, cálcio e magnésio.

Estudos com isótopos no AAC restringem-se aos isótopos de urânio. A razão de atividade ${ }^{234} \mathrm{U} / 238 \mathrm{U}$, na região do entorno de Manaus, decresce no sentido do fluxo subterrâneo, 
o que foi atribuído pelos autores à maior interação água-rocha-solo (Silva e Bonotto, 2006).

\section{MATERIAIS E MÉTODOS}

Os dados obtidos incluíram perfis construtivos de poços tubulares, dados hidroquímicos e demais informações disponíveis na plataforma SIAGAS (Sistema de Informações de Águas Subterrâneas)/CPRM (banco de dados online mantido pelo Serviço Geológico do Brasil - CPRM). Também se obtiveram dados litológicos e estratigráficos de poços fornecidos pela Petrobras, nas bacias do Amazonas e Solimões, totalizando 1.505 pontos de água nos municípios estudados (Iranduba, Manacapuru, Careiro, Manaquiri, Beruri, Anamã, Anori, Caapiranga, Codajás, Coari e Novo Airão).

Campanhas de campo foram realizadas em novembro de 2015 e abril de 2016, em Iranduba, Manacapuru, Careiro, Manaquiri e Manaus. Coletaram-se amostras de água subterrânea de 16 poços tubulares profundos para análise química em laboratório. Em outros 22 poços mediram-se parâmetros físico-químicos in situ (temperatura, $\mathrm{pH}, \mathrm{CE}, \mathrm{Eh}$ e alcalinidade) (Figura 2). Mediu-se o nível estático e/ou dinâmico, quando possível. A maioria dos poços amostrados é de abastecimento público. Sua profundidade varia de 80 a $236 \mathrm{~m}$. Em alguns poços coletaram-se amostras nos dois períodos regionais climáticos: período de chuvas e cheia dos rios, entre dezembro e junho; período de seca e rios em vazante, entre julho e novembro. Também foram coletadas amostras dos rios Solimões e Negro e da chuva local.

Os cátions e ânions maiores foram analisados por cromatografia de íons, enquanto os metais foram analisados por espectrometria de massa com plasma indutivamente acoplado (ICP-MS). Também foram realizadas análises isotópicas de $\delta^{18} \mathrm{O}$ e $\delta^{2} \mathrm{H}$, em nove amostras, em relação ao padrão V-SMOW. As análises físico-químicas de isótopos estáveis foram realizadas no Laboratório de Caracterização de Águas (LAB-ÁGUAS) da Pontifícia Universidade Católica do Rio
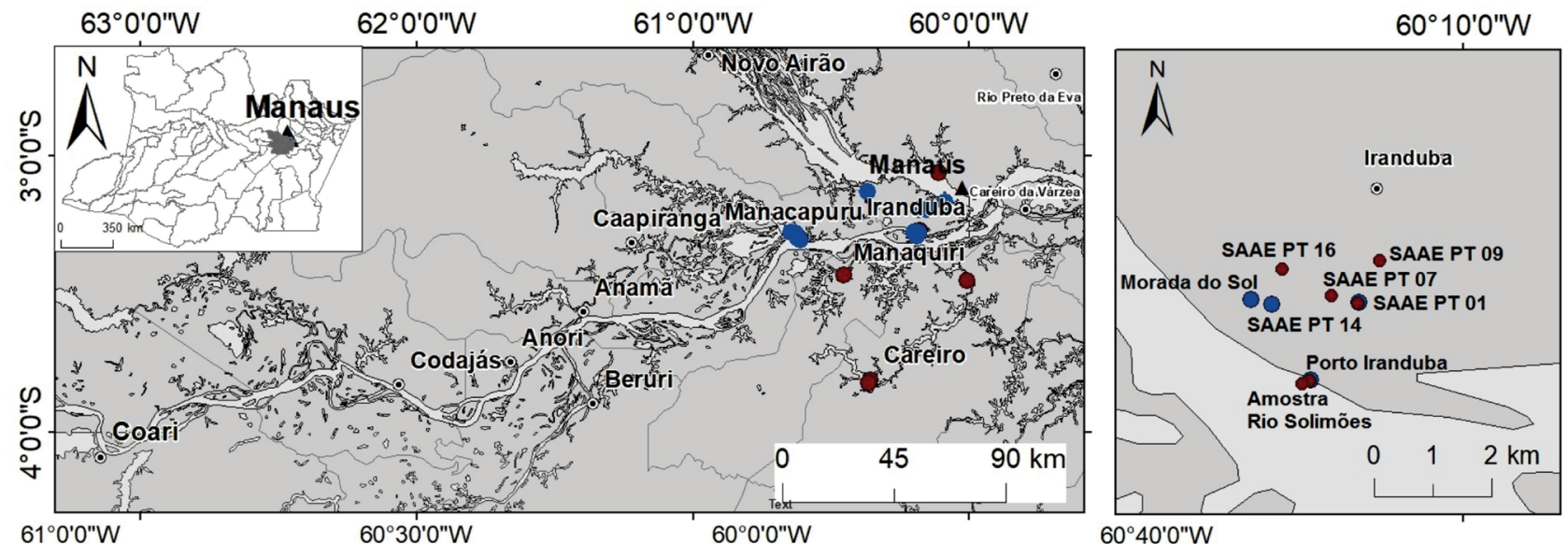

$60^{\circ} 40^{\prime} 0^{\prime \prime} \mathrm{W}$

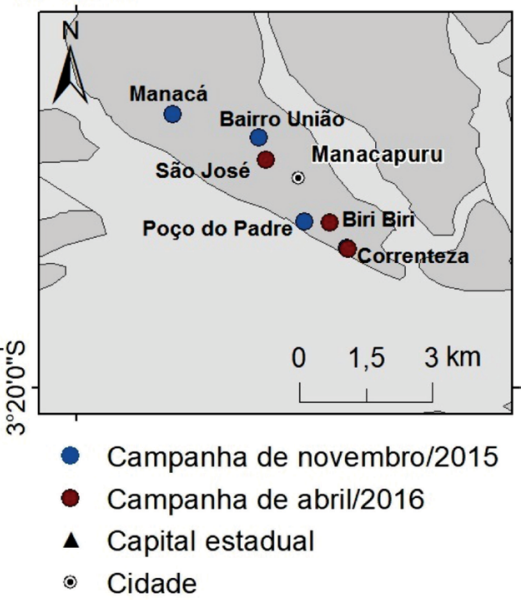

Figura 2. Localização da área de trabalho, no estado do Amazonas, com destaque para a área amostrada durante as campanhas de campo realizadas a sudoeste de Manaus. 
de Janeiro (PUC-RJ). A concentração de ${ }^{13} \mathrm{C}\left(\delta^{13} \mathrm{C}\right)$ foi medida em duas amostras por meio do espectrômetro de massa de razão isotópica, em relação ao padrão V-PDB, com desvio padrão de $\pm 0,3 \%$. A concentração de ${ }^{14} \mathrm{C}$ foi medida com o espectrômetro de aceleração de massa. A análise de trítio $\left({ }^{3} \mathrm{H}\right)$ foi realizada por espectrometria de cintilação líquida após enriquecimento eletrolítico da amostra. As análises de trítio, ${ }^{14} \mathrm{C} \mathrm{e}{ }^{36} \mathrm{Cl}$ foram realizadas no laboratório Hydroisotop $\mathrm{GmbH}$, na Alemanha.

A partir dos dados de ${ }^{14} \mathrm{C}$, foram realizadas estimativas da idade das águas subterrâneas $(\mathrm{t})$, conforme a Equação 1 (Clark e Fritz, 1997). As idades do modelo de ${ }^{14} \mathrm{C}$ foram corrigidas pelo modelo isotópico de Pearson (1965) (Equação 2), utilizando os valores de $\delta^{13} \mathrm{C}\left({ }^{13} \mathrm{C} /{ }^{12} \mathrm{C}\right)$ medidos nas amostras e valores teóricos (Clark e Fritz, 1997).

$\mathrm{t}=8033 \ln \frac{\mathrm{A}_{0}}{\mathrm{~A}}$

Em que:

$\mathrm{A}_{0}=$ atividade inicial da atmosfera $(\mathrm{pMC}) ;$

$\mathrm{A}=$ atividade de ${ }^{14} \mathrm{C}$ medida na amostra (pMC)

$\mathrm{A}_{0 \text { Pearson }}=\frac{\left(\mathrm{A}_{\mathrm{g}}-\mathrm{A}_{\mathrm{c}}\right)\left(\delta_{\mathrm{T}}-\delta_{\mathrm{C}}\right)}{\left(\delta_{\mathrm{g}}-\delta_{\mathrm{c}}\right)}+\mathrm{A}_{\mathrm{C}}$

Em que:

$\mathrm{A}_{\text {oPearson }}=$ atividade de ${ }^{14} \mathrm{C}$ em pMC;

$\delta=\delta^{13} \mathrm{C}$;

$\mathrm{T}=$ carbono inorgânico dissolvido total (amostra);

$\mathrm{g}=$ gás $\mathrm{CO}_{2}$ do solo;

$\mathrm{c}=$ minerais carbonáticos.

Devido a variações da concentração de ${ }^{14} \mathrm{C}$ na atmosfera, ao longo do tempo, após a correção pelo modelo isotópico as idades necessitaram ser calibradas, para que representassem anos do calendário (Hatfield e Patrick, 2016). A calibração foi realizada com uso do software Calib 7.1 (Stuiver et al., 2018), utilizando a base de dados Intcal13.

No modelo de ${ }^{36} \mathrm{Cl}$, a idade foi estimada segundo a Equação 3 (Bentley et al., 1986). A razão ${ }^{36} \mathrm{Cl}^{-\mathrm{Cl}^{-}}\left(\mathrm{R}_{36}\right)$ inicial na área de recarga foi estimada em $300 \times 10^{-15}$ pela impossibilidade da medida direta na região (Davis et al., 2003). $\mathrm{O}$ valor da razão no equilíbrio secular $\left(\mathrm{R}_{\mathrm{se}}\right)$ utilizado foi de $5 \times 10^{-15}$, típico de arenitos em grandes bacias sedimentares (Clark e Fritz, 1997).

$t=\frac{-1}{\lambda^{36} \mathrm{Cl}} \ln \frac{\mathrm{C}_{\mathrm{t}}\left(\mathrm{R}_{\mathrm{t}}-\mathrm{R}_{\mathrm{se}}\right)}{\mathrm{C}_{0}\left(\mathrm{R}_{0}-\mathrm{R}_{\mathrm{se}}\right)}$

Em que:

$\mathrm{R}_{\mathrm{t}}=$ razão ${ }^{36} \mathrm{Cl} / \mathrm{Cl}$ medida após o tempo t;

$\mathrm{R}_{\mathrm{se}}=$ razão ${ }^{36} \mathrm{Cl} / \mathrm{Cl}$ no equilíbrio secular (para um dado aquífero);

$\mathrm{R}_{0}=$ razão ${ }^{36} \mathrm{Cl} / \mathrm{Cl}$ cosmogênica inicial;

$\lambda^{36} \mathrm{Cl}=$ constante de decaimento do ${ }^{36} \mathrm{Cl}\left(\ln 2 / \mathrm{t}_{1 / 2}=2,303 \times 10^{-6}\right)$;
$\mathrm{C}_{\mathrm{t}}=$ concentração de $\mathrm{Cl}^{-}$medida na amostra (átomos/L);

$\mathrm{C}_{0}=$ concentração de $\mathrm{Cl}^{-}$inicial na água de recarga (átomos/L).

A interpretação dos dados obtidos foi realizada com o auxílio de gráficos e diagramas, como diagramas binários, diagrama de Piper (1944) etc., permitindo a caracterização hidrogeoquímica das amostras obtidas.

Realizou-se também um exercício de modelagem hidrogeoquímica para testar algumas hipóteses sobre o funcionamento do aquífero na região, com o auxílio do software PHREEQCI 3.3.7 (Parkhurst e Appelo, 2013). Foram calculados os índices de saturação mineral (IS) das amostras e, posteriormente, realizada uma simulação com o modelo de mescla (módulo MIX do programa), utilizando amostras da água subterrânea profunda e da água da chuva local, supondo um efeito de mistura e diluição progressiva, à luz dos dados disponíveis. Após a análise integrada de todos os dados foi elaborado um modelo conceitual da região, que é proposto de acordo com os dados disponíveis até o momento.

\section{RESULTADOS E DISCUSSÃO}

\section{Características geoquímicas básicas}

Na Tabela 1, apresentam-se os principais resultados das análises químicas e medidas físico-químicas in situ realizadas nas amostras dos municípios de Iranduba, Manacapuru, Careiro, Manaquiri e Manaus. Quanto aos parâmetros físico-químicos, verificou-se que as temperaturas variaram de 27,4 a $31,4^{\circ} \mathrm{C}$, com média de $29^{\circ} \mathrm{C}$. Não houve boa correlação com os valores de temperatura do ar $\left(\mathrm{r}^{2}=0,45\right)$, medidos simultaneamente. Abaixo de cerca de $20 \mathrm{~m}$ de profundidade, a temperatura do solo independe do clima da região, passando a ser influenciada pelo grau geotérmico local (Ward, 1985; Corcóvia e Celligoi, 2012). Observou-se esse fato na temperatura das águas dos poços profundos, cuja variação em Iranduba (entre $28 \mathrm{e}$ $28,6^{\circ} \mathrm{C}$ ) e Manacapuru $\left(28\right.$ a $\left.29,1^{\circ} \mathrm{C}\right)$ foi de $1,1^{\circ} \mathrm{C}$, no máximo.

$\mathrm{O}$ pH das águas subterrâneas variou de 3,58 a 7,18. Em Manacapuru e no poço do distrito de Araçá, em Careiro, $\mathrm{o} \mathrm{pH}$ ficou próximo à neutralidade, enquanto as demais amostras apresentaram caráter francamente ácido. Isto parece indicar um ambiente de circulação hidrogeoquímico distinto quanto ao substrato geológico e influência variável das águas meteóricas em cada área.

Observou-se o contraste entre o $\mathrm{pH}$ das águas do rio Negro, ácido, e do rio Solimões, mais próximo à neutralidade, como já apontado por diversos autores (Sioli, 1975; OTCA, 2006), mas não se observou esse efeito sobre a geoquímica dos aquíferos adjacentes, exceto em poços nas várzeas do rio Solimões.

ACE variou de 18 a $884 \mu \mathrm{S} . \mathrm{cm}^{-1}$ nas águas subterrâneas, com média de $416 \mu \mathrm{S} . \mathrm{cm}^{-1}$, e de 5 a $88 \mu \mathrm{S} . \mathrm{cm}^{-1}$ nas águas 


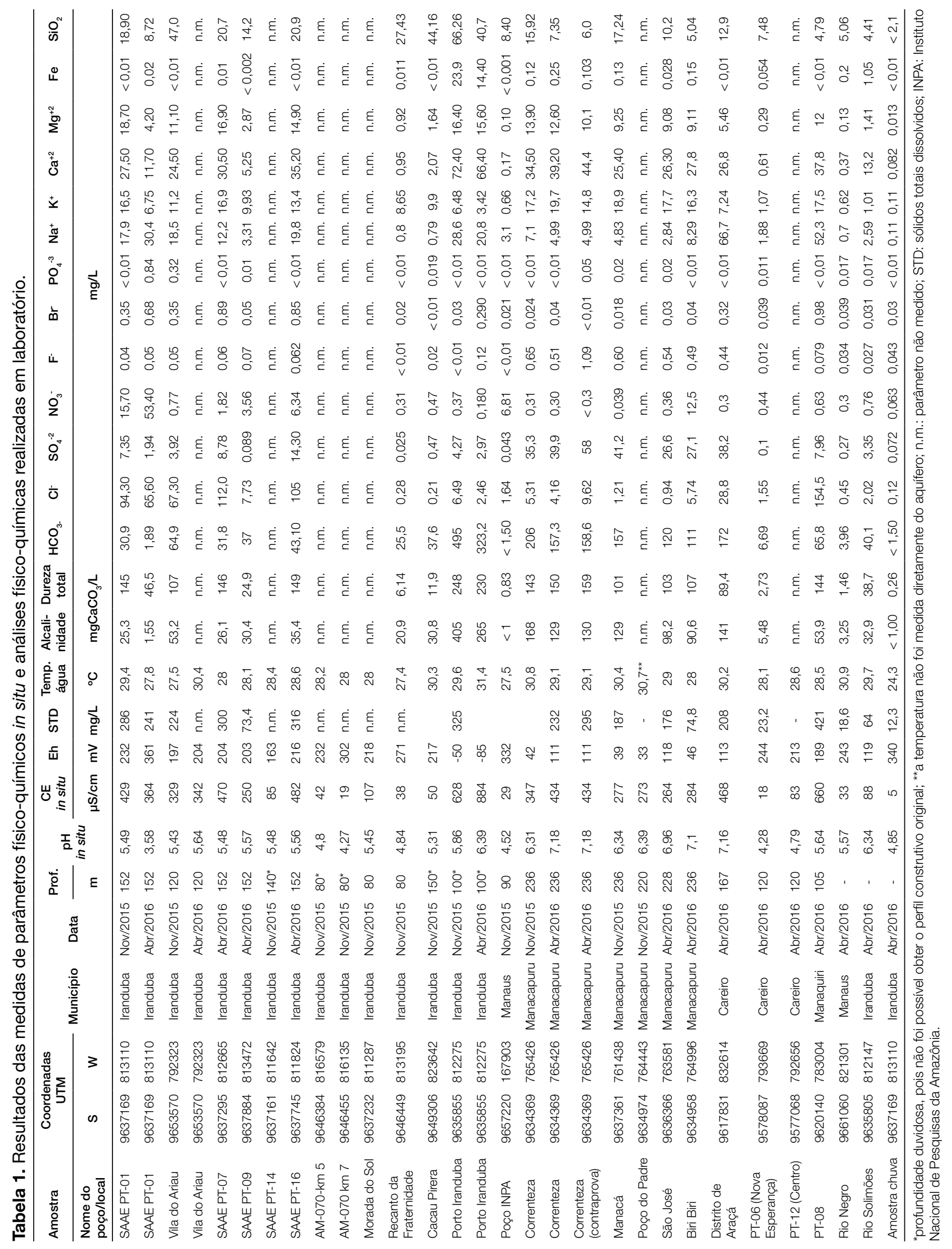


superficiais e na precipitação pluviométrica, evidenciando uma faixa ampla de variação da mineralização nas águas locais. Em geral, com o aumento da profundidade ocorrem águas mais mineralizadas, e a média elevada registrada deve-se à relativamente elevada profundidade dos poços, como em Iranduba e Manacapuru, principalmente. O maior tempo de residência no aquífero permite uma maior interação água-rocha, pois as águas podem ser provenientes de fluxos regionais, viajando por grandes distâncias nos aquíferos, como sugerido por Rosário et al. (2016). Outra possibilidade é que a Formação Nova Olinda, subjacente, com seus conhecidos níveis evaporíticos, tenha influência na maior salinidade dos níveis inferiores do aquífero.

Altos valores de CE são considerados atípicos para o AAC por Silva e Silva (2007) e Aguiar e Marmos (2010). Estes autores consideram em seus estudos os níveis superiores da FAC, na região de Manaus, onde o AAC é aflorante e livre, com águas pouco mineralizadas, de recarga recente e rápida infiltração. Contudo, águas com CE mais elevada são relatadas em Manacapuru, Iranduba e Novo Airão por Miranda et al. (2011) e outros. Tais autores atribuem isso à influência de águas mais mineralizadas da Formação Nova Olinda, sotoposta. O que se observou de fato é que uma maior salinidade do AAC é comum na região, principalmente com o aumento da profundidade dos poços tubulares, a sudoeste de Manaus.

O potencial de oxirredução (Eh) apresentou valores positivos em 14 dos pontos analisados, variando de +46 a +361 mV, indicando assim condições de ambiente oxidante, as quais são condizentes com os resultados de Silva e Bonotto (2006) em Manaus. Apenas no Porto de Iranduba a amostra apresentou valor negativo $(-85 \mathrm{mV})$, indicando um ambiente redutor, possivelmente devido a processos biológicos restritos ao local do poço, haja vista a grande quantidade de ferro dissolvido $(14,4 \mathrm{mg} / \mathrm{L})$ na amostra, com incrustações na tubulação e proximidades do poço. Esses processos biológicos, pela ação de ferrobactérias, e altas concentrações de ferro e manganês, são comuns nas regiões de várzea do rio Solimões (Azevedo, 2006). Os níveis com esse caráter redutor podem ser os mais rasos na sequência atravessada pelo poço.

A alcalinidade medida in situ variou de 20 a $124 \mathrm{mg} / \mathrm{L} \mathrm{CaCO}_{3}$, com média de 52,8 mg/L CaCO 3 , sendo bem maior nos poços do distrito de Araçá e do bairro São José. A alcalinidade medida em laboratório variou de 1,55 a $265 \mathrm{mg} / \mathrm{L} \mathrm{CaCO}_{3}$, com média de 79,7 mg/ $\mathrm{L} \mathrm{CaCO}_{3}$, indicando grandes diferenças no ambiente geoquímico de circulação das águas. Silva e Silva (2007) apontaram a alcalinidade variando de 1,22 a $30,50 \mathrm{mg} / \mathrm{L}$ de $\mathrm{CaCO}_{3}$ em Iranduba, o que é compatível com o estudo, à exceção da citada amostra do Porto. Isso possivelmente se deve aos fatores biológicos citados anteriormente, que tendem a liberar bicarbonato na água. Em Manacapuru e no distrito de Araçá, os valores de alcalinidade foram maiores que os encontrados nas outras localidades. Tal diferença tem relação com o substrato geológico e o ambiente de circulação das águas subterrâneas, distinto naquelas localidades.

As águas subterrâneas da região foram classificadas em três grupos geoquímicos principais - fácies geoquímicas (Figura 3). No grupo 1, encontram-se amostras do tipo cloretada-cálcica (secundariamente magnesiana ou sódica) mais mineralizadas, com STD médio de $341 \mathrm{mg} / \mathrm{L}$. São amostras provenientes dos poços profundos de Iranduba (cerca de $150 \mathrm{~m}$ de profundidade) e do poço PT-08 (105 m de profundidade), em Manaquiri. Podem representar águas mais antigas, com maior mineralização e crescente concentração em cloretos. As águas cloretadas representam o estágio final de evolução hidrogeoquímica das águas subterrâneas em grande escala, podendo ser provenientes de fluxos regionais profundos. Há, como já comentado, a hipótese de influência dos níveis de halita da Formação Nova Olinda, rica nesse mineral em seus horizontes superiores (Scomazzon, 2004).

No grupo 2, enquadram-se as águas bicarbonatadas-cálcicas (secundariamente magnesianas ou potássicas). As amostras deste grupo foram separadas em dois subgrupos:

- águas bicarbonatadas-cálcicas e magnesianas, mais salinizadas (STD médio de $185 \mathrm{mg} / \mathrm{L}$ ), dos poços profundos de Manacapuru e Porto de Iranduba;

- águas bicarbonatadas-cálcicas e potássicas, com baixa mineralização $\left(\mathrm{CE}<100 \mu \mathrm{S} . \mathrm{cm}^{-1}\right)$, típicas de recarga recente na porção mais rasa do AAC, representando águas mais jovens (Beato et al., 1999), pela dissolução do gás carbônico presente no solo.

A maior mineralização observada em poços mais profundos indica águas mais antigas e, talvez, interação com carbonatos dos níveis superiores da Formação Nova Olinda, levando a um caráter bicarbonatado, mesmo em águas significativamente mais antigas e de circulação regional.

O grupo 3 é composto de águas bicarbonatadas-sódicas de salinidade variável. Há amostras com baixa mineralização, como o poço PT-06 (Careiro), de rápida infiltração no aquífero e baixo tempo de residência. Essa característica é muito comum na porção livre do AAC (ANA, 2005). Em Careiro existe, contudo, uma cobertura da Formação Içá (CPRM, 2006; IBGE, 2011). Isso não altera a significativa influência meteórica, mesmo em horizontes relativamente profundos (cerca de $120 \mathrm{~m}$ ), que já devem corresponder à FAC. Águas mais mineralizadas, como no poço de Araçá, por exemplo, apontam a uma maior interação e tempo de residência no aquífero, sugeridos também pelo $\mathrm{pH}$ tendendo à neutralidade. $\mathrm{O}$ caráter bicarbonatado sódico desta amostra indica enriquecimento de sódio em função de processos de hidrólise ou de troca iônica (Silva Jr. e Cristo, 2014). 
Esses dados demonstram que o AAC sofre intensa recarga nas áreas em que aflora e possivelmente também em áreas nas quais possui uma pequena cobertura da Formação Içá, a oeste, devido ao elevado índice pluviométrico da região e a condições favoráveis à recarga das coberturas superficiais. Dessa forma, suas águas são constantemente renovadas e apresentam características químicas correlatas às da precipitação. Já em níveis mais profundos, a influência meteórica diminui e os processos de interação água-rocha e, possivelmente, a influência de fluxos regionais podem ocorrer (Rosário et al., 2016), ficando refletidas na maior mineralização destas águas.

\section{Interpretação conceitual do aquífero e razões iônicas}

As razões ou relações iônicas fornecem um modo efetivo para a interpretação do funcionamento hidrogeológico do aquífero. A seguir, apresentam-se alguns resultados dessa interpretação.

Quanto à razão iônica $r \mathrm{Cl}^{-} / r \mathrm{HCO}_{3}^{-}$(o símbolo $r$ indica valores em meq/L), as amostras da região foram divididas em três grupos, segundo as origens interpretadas (Figura 4):

- grupo 1: valores baixos da razão $r \mathrm{Cl}^{-} / r \mathrm{HCO}_{3}^{-}$, situando-se sob a linha da razão linear 1:1, apontando para águas tipicamente continentais e originadas por recarga local, com alta influência de águas meteóricas e tempo de residência curto a médio no aquífero (Han et al., 2010). Exceto nos poços profundos de Manacapuru e Iranduba, tais amostras são geralmente provenientes de poços rasos da região, daí o caráter bicarbonatado e a influência de águas meteóricas sobre a água subterrânea (Silva Jr. e Cristo, 2014);

- grupo 2: valores de $r \mathrm{Cl}^{-} / r \mathrm{HCO}_{3}^{-}$variando entre 1 e 5, com um valor anomalamente mais alto de 59 no poço SAAE PT 01, de Iranduba. Os poços têm maior profundidade e indicam fontes de $\mathrm{Cl}^{-}$em níveis mais profundos, pela dissolução de halita e outros sais de evaporitos. O enriquecimento em cloreto sugere maior tempo de residência e a contribuição de um fluxo regional: a alta solubilidade do cloreto e o lento movimento das águas no aquífero provocam aumentos gradativos e constantes do teor de $\mathrm{Cl}^{-}$na direção de fluxo (Feitosa et al., 2008);

- grupo 3: valores de $r \mathrm{Cl}^{-} / r \mathrm{HCO}_{3}{ }^{-}$altos em águas muito pouco mineralizadas. As amostras ocorrem onde o aquífero AAC é aflorante. Isso acontece devido a processos naturais das águas meteóricas da região, como evaporação de águas empoçadas. A matéria orgânica e os ácidos húmicos abundantes no solo podem fazer com que a água se torne muito ácida. O baixo conteúdo de $\mathrm{HCO}_{3}^{-}$, devido à elevada acidez, leva a valores mais altos da razão $r \mathrm{Cl}^{-} / r \mathrm{HCO}_{3}{ }^{-}$em águas pouco mineralizadas

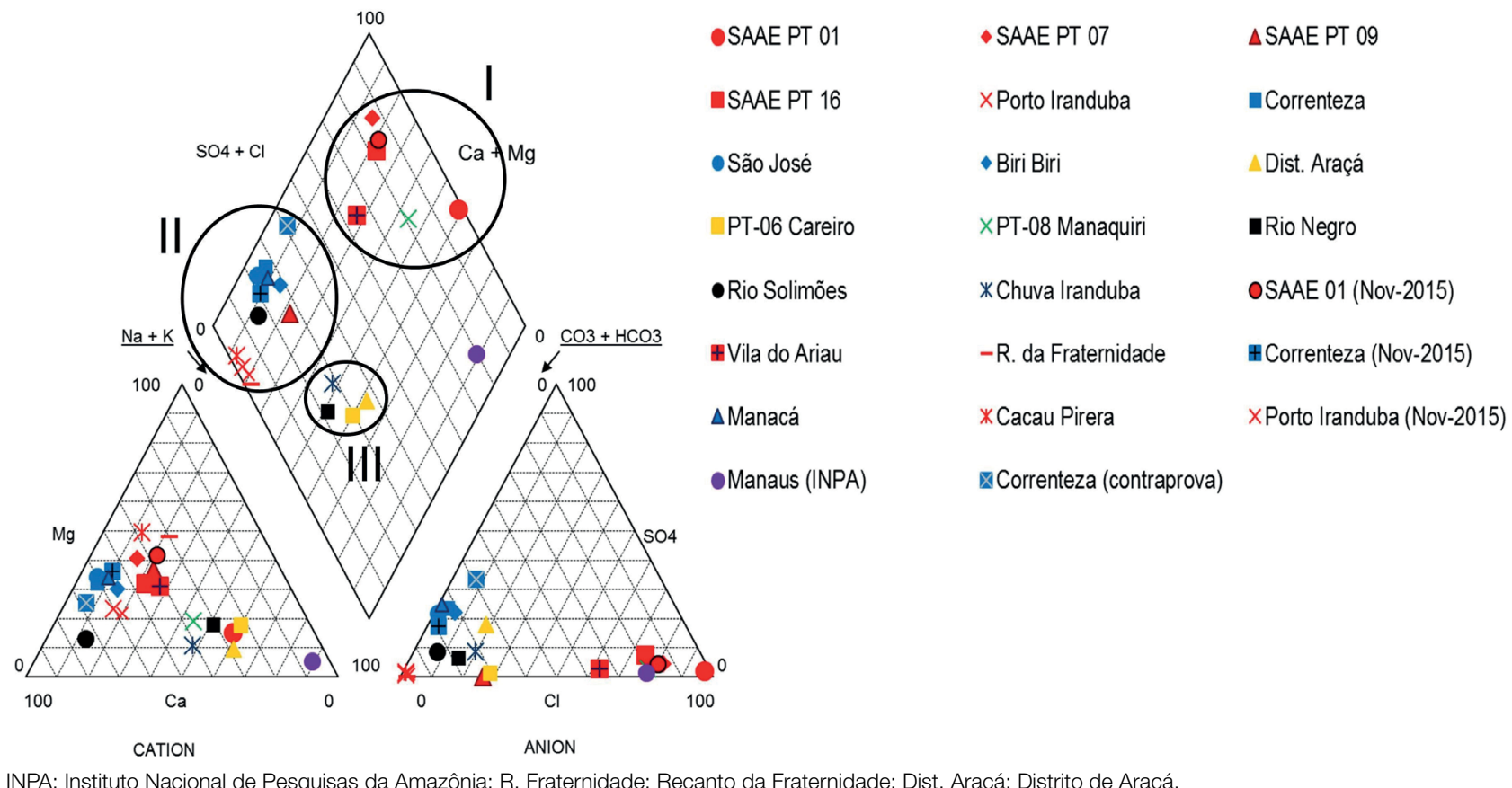

Figura 3. Diagrama de Piper das amostras coletadas em campo, as quais foram divididas em três grupos principais (I, II, III). 
da região. O teor crescente de cloretos em poços rasos também pode ser indício de contaminação e de poços mal construídos.

A razão $r \mathrm{Cl} / r \mathrm{Br}$ tende a refletir a razão da fonte de salinidade original ou do último processo a que foi submetida a água, dada a natureza conservativa desses íons (Davis et al., 1998). Utilizou-se o método proposto por Alcalá e Custodio (2008) para a análise dos dados dessa razão. Foram divididos três grupos principais, destacados na Figura 5:

- grupo 1: amostras com baixos valores de $r \mathrm{Cl}^{-} / r \mathrm{Br}^{-}$ (entre 9 e 175) e baixas concentrações de $\mathrm{Cl}^{-}$(entre 0,12 e 2,02 $\mathrm{mg} / \mathrm{L}$ ), provavelmente originadas de recarga por águas meteóricas, com rápida infiltração no aquífero. Valores menores que 200 dessa razão são característicos da precipitação atmosférica, mormente em grandes massas continentais (Mullaney et al., 2009). Este grupo compreende poços que explotam horizontes superiores do aquífero, água dos rios Solimões, Negro e chuva local e duas amostras de poços profundos de Manacapuru (Manacá e São José). Mesmo nestes poços mais profundos, com maior mineralização, pode haver influência de águas meteóricas, pela presença de filtros em profundidades mais rasas ou falhas e fraturas que gerem caminhos preferenciais de fluxo entre os horizontes rasos e profundos;
- grupo 2: aumento da razão $r \mathrm{Cl}^{-} / r \mathrm{Br}$ e da concentração de cloreto e taxa $r \mathrm{Cl}^{-} / r \mathrm{Br}$ entre 200 e 500 . Os dados sugerem tratar-se de águas subterrâneas com maior interação com o aquífero. Nesse grupo, incluem-se amostras de poços profundos de Manacapuru e uma amostra de Iranduba (SAAE 09). O perfil construtivo deste poço (SAAE 09), com filtros em camadas mais rasas (de 82 a $139 \mathrm{~m}$ ), pode ser responsável por esta característica da amostra;

- grupo 3: valores mais altos de $r \mathrm{Cl}^{-} / r \mathrm{Br}^{-}$e de cloreto, incluindo alguns valores semelhantes aos da água do mar (amostra SAAE 01). Incluem-se amostras dos poços profundos de Iranduba $(150 \mathrm{~m})$ e dos municípios de Manaquiri e Careiro (poços PT-08 e distrito de Araçá, respectivamente). Em geral, razões $r \mathrm{Cl} / r \mathrm{Br}$ acima de 200 costumam indicar fontes litológicas de $\mathrm{Cl}^{-}$, como halita e outros sais (Bozdag e Göçmez, 2016). Segundo Hofmann e Cartwright (2013), a observação de que a razão $r \mathrm{Cl}^{-} / r \mathrm{Br}$ não aumenta muito, simultaneamente ao aumento na concentração de $\mathrm{Cl}^{-}$, indica que não deve haver dissolução de halita significativa na área do estudo.

A semelhança da razão $r \mathrm{Cl}^{-} / r \mathrm{Br}$ com a da água do mar, observada em algumas amostras, pode indicar, na verdade, a influência de um sistema aquífero com longa extensão do fluxo subterrâneo, já que, com a evolução do trânsito da

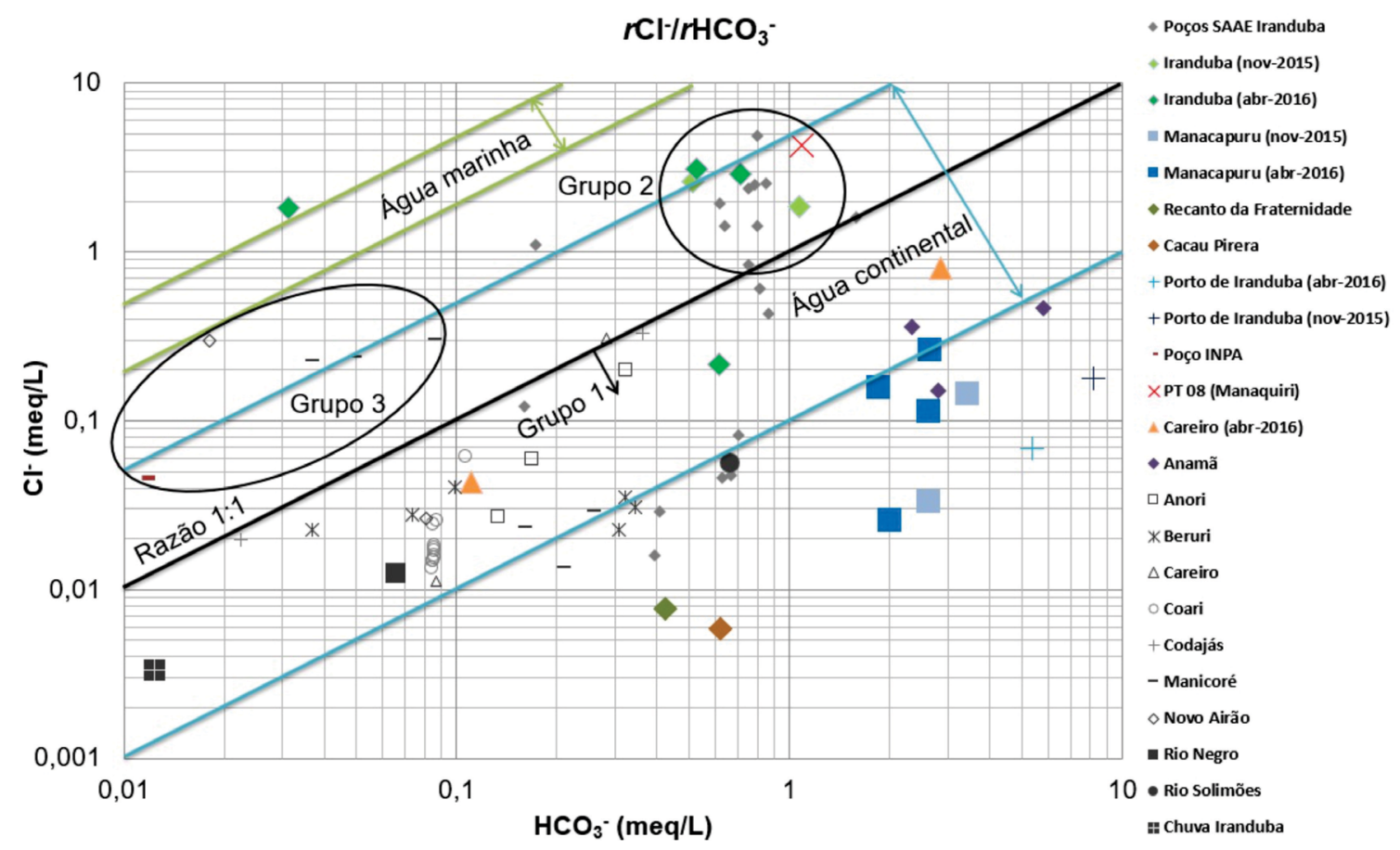

Figura 4. Gráfico relacionando os teores de cloreto e bicarbonato (em meq/L) de amostras analisadas nos municípios em estudo. As amostras em tons de cinza foram obtidas no banco de dados SIAGAS/CPRM. 
água, ela tende a adquirir características semelhantes às da água marinha (Nwankwoala e Udom, 2011). Para avaliar essa hipótese, as análises isotópicas para datação da água foram cruciais.

Aparentemente ocorre uma tendência de evolução da salinidade (Figura 5), desde águas diluídas, claramente de origem meteórica, a águas algo mais mineralizadas (região de Manacapuru), chegando até amostras mais salinas e ricas em cloreto, mostrando semelhança com águas marinhas diluídas (região de Iranduba). Esta evolução parece ocorrer no sentido do fluxo subterrâneo regional, de oeste para leste. Tal fato apontaria para a existência de um fluxo regional, nos níveis mais profundos do AAC.

A razão $r \mathrm{HCO}_{3}^{-} / r \mathrm{Ca}^{2+}$ é utilizada a fim de fornecer indicação da ocorrência de processos de dissolução de carbonatos na água subterrânea. Quando a dissolução de carbonatos é um processo dominante, a razão segue uma tendência 1:1, com alta correlação entre os íons. Observando os dados da Figura 6, não há uma clara correlação entre os íons bicarbonato e cálcio. Em amostras menos mineralizadas e mais influenciadas por águas meteóricas (Cacau Pirera e
SAAE PT 09), o $\mathrm{HCO}_{3}^{-}$predomina em relação aos outros ânions. Interpreta-se que a predominância do bicarbonato e os consequentes valores mais altos de $r \mathrm{HCO}_{3}^{-1 / \mathrm{Ca}^{2+}}$ devem-se justamente à atuação dos processos de recarga, com a dissolução de $\mathrm{CO}_{2}$ do solo, que ocorre nos horizontes mais rasos. Assim, esta razão pode indicar a presença de águas originadas na recarga recente, na medida em que a razão $\mathrm{rHCO} 3 / \mathrm{rCa}$ se torna mais alta. Em amostras dos poços profundos de Manacapuru, os valores de $r \mathrm{HCO}_{3}^{-} / r \mathrm{Ca}^{2+}$ variaram entre 1 e 1,5, sugerindo que a dissolução de carbonatos teria importância secundária no aquífero, principalmente na região de Manacapuru. Nas demais amostras ocorrem maiores teores de $\mathrm{Ca}^{2+}$, prevalecendo processos de interação água-rocha mais prolongados, com a dissolução de silicatos cálcicos e/ou trocas iônicas.

\section{Análises isotópicas}

Quanto à distribuição de isótopos ambientais (oxigênio-18 e deutério), observa-se que a chuva na Região Amazônica é muito diversa e não existe um comportamento único.

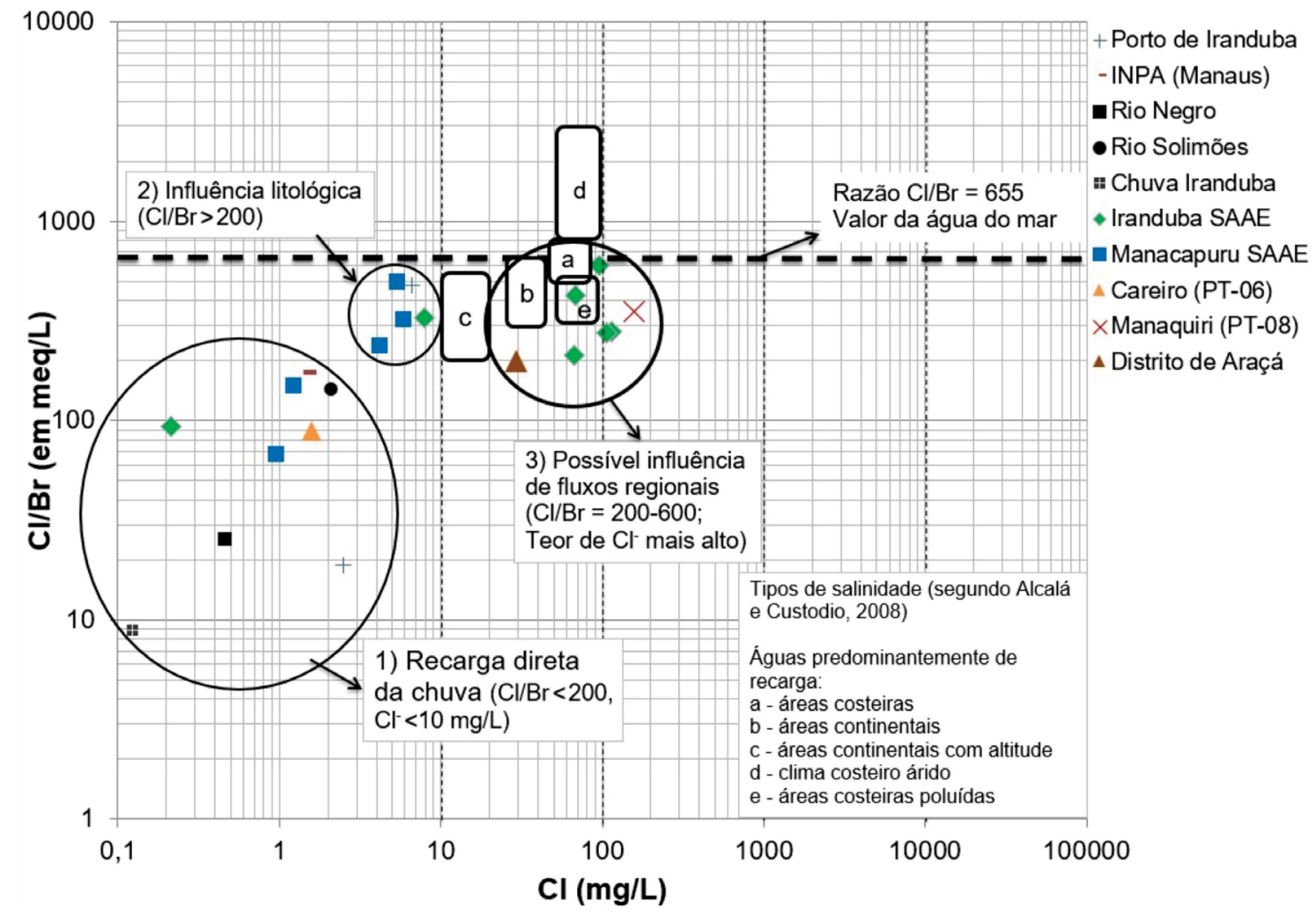

INPA: Instituto Nacional de Pesquisas da Amazônia.

Figura 5. Gráfico da razão $r \mathrm{Cl}^{-} / \mathrm{rBr}$ (em meq/L) pela concentração de $\mathrm{Cl}$ (em mg/L) para as amostras coletadas em campo. Os grupos 1 a 3 indicam a provável origem da salinidade. As letras indicam subgrupos dentro da origem primária (águas de recarga), segundo Alcalá e Custodio (2008). 
Há uma variação sazonal bem marcada na região, com chuvas isotopicamente mais leves predominantes no período de inverno regional, mais chuvoso (dezembro a maio), e chuvas mais pesadas no período de verão e seca regional (junho a novembro). As chuvas isotopicamente mais pesadas estariam relacionadas à influência da evapotranspiração da vegetação, que ocorre geralmente em condição de clima menos chuvoso, entre julho e novembro. O processo de evapotranspiração da floresta, segundo os principais estudos, é responsável por aproximadamente $50 \%$ do vapor d'água que forma a precipitação na Amazônia (Dall'olio et al., 1979; Salati et al., 1979).

O maior fracionamento isotópico e, consequentemente, as chuvas mais depletadas são atribuídos a eventos de chuvas mais intensas, originadas em frentes frias regionais, principalmente entre dezembro e maio (Mazor, 1991; Honório, 2007). A amostra de chuva coletada no período regional chuvoso confirmou esta configuração climática local ao apresentar-se bastante depletada. Em um estudo na região de Urucu, Souza et al. (2015) encontraram configuração climática semelhante, denotada pela composição isotópica das águas meteóricas locais.

$\mathrm{Na}$ Figura 7, as amostras de ${ }^{18} \mathrm{O}$ e ${ }^{2} \mathrm{H}$ coletadas em poços profundos de Manacapuru (Correnteza e São José), Iranduba
(SAAE 01, 09 e Vila do Ariau) e Careiro são apresentadas, incluindo-se amostras de chuva de Manaus no período de 1965 a 1990 e dos rios Solimões e Negro, obtidas do banco de dados da International Atomic Energy Agency — IAEA (IAEA e WMO, 2017), além das retas meteóricas mundial (RMM) e local (RML). Calculou-se também a média ponderada da precipitação (MPP), que é a ponderação de $\delta^{18} \mathrm{O}$ e $\delta^{2} \mathrm{H}$ pelo acumulado pluviométrico total. Segundo Kehew (2001), padrões semelhantes ao da Figura 7, com chuvas bastante dispersas ao longo da reta meteórica, são típicos de climas muito úmidos.

A água subterrânea apresentou comportamento mais homogêneo, principalmente entre amostras do mesmo tipo hidroquímico. Além disso, em geral, apresentou valores muito próximos da MPP, da RMM e da RML (Figura 7). Este padrão, provavelmente, resulta de processos sucessivos de mistura com águas meteóricas ao longo do tempo, levando a um equilíbrio da composição isotópica da água subterrânea. Assim, os valores de $\delta^{18} \mathrm{O}$ e $\delta^{2} \mathrm{H}$ muito próximos aos das águas meteóricas indicam clara influência destas nas águas subterrâneas. Porém, não se pode afirmar que sejam águas recentes, pois águas mais antigas podem apresentar configuração isotópica semelhante à das águas de chuva atuais, mesmo que isoladas da atmosfera por muito tempo.

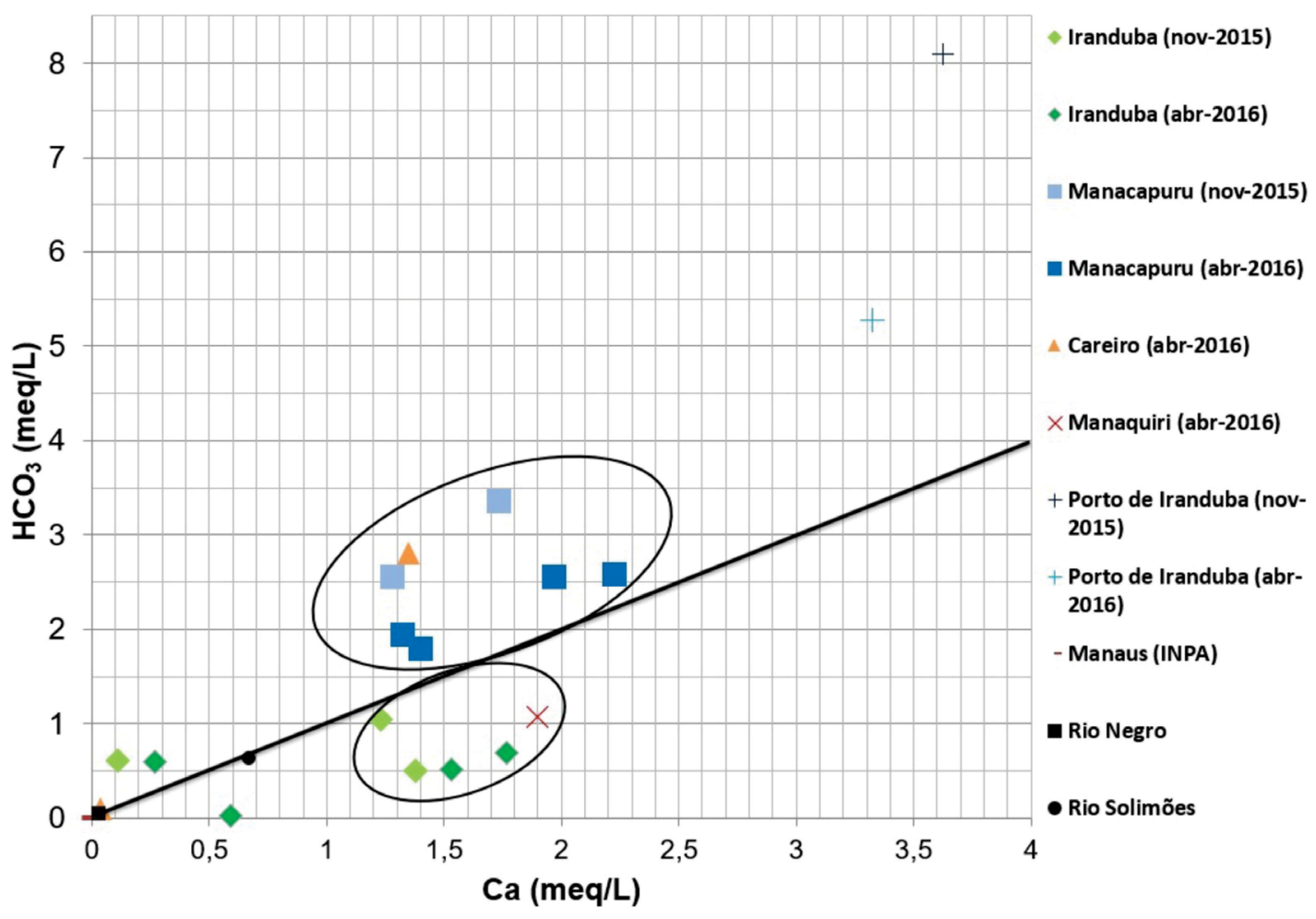

INPA: Instituto Nacional de Pesquisas da Amazônia.

Figura 6. Gráfico relacionando os teores de bicarbonato e cálcio (em meq/L) nas amostras das duas campanhas de campo. A reta indica a razão 1:1 esperada para a predominância da dissolução de carbonatos. 
Assim, as águas subterrâneas da região podem ter sido recarregadas em condições de clima úmido, semelhante ao atualmente observado na Amazônia. Também é possível afirmar que há ausência de processos evaporativos significativos nas águas subterrâneas, sugerindo a possibilidade da ocorrência de dissolução progressiva de sais como responsável pelo aumento da salinidade, enquanto a configuração isotópica mantém-se estável (Li et al., 2008).

No aquífero Içá-Solimões, na região de Urucu, Souza et al. (2015) encontraram um padrão isotópico semelhante ao das águas subterrâneas do AAC, com composição mais homogênea e menor variabilidade em relação ao observado nas águas meteóricas e em águas superficiais da região, além da semelhança com as águas meteóricas (amostras entre as RMM e RML). Isso denota a semelhança nos processos de recarga desses dois sistemas aquíferos, altamente influenciados pelo clima da região, com altos índices pluviométricos, o que promove abundante recarga direta pela chuva, com pouca ou nenhuma evaporação. Estes autores também observaram alta influência meteórica nas águas superficiais, com baixa evaporação, além de inferirem alguma influência de rios locais na recarga ao aquífero Içá-Solimões.

Na Figura 7, observa-se que os rios Solimões e Negro apresentam composição muito próxima das águas meteóricas locais, com tendência de proximidade com a MPP, sem apresentar evidências de processos evaporativos, assim como observado na província de Urucu. No entanto, não foi possível identificar contribuições destes corpos hídricos aos aquíferos no presente estudo, por não terem sido realizadas análises isotópicas nos mesmos, nem ter sido monitorado o efeito sazonal nas águas subterrâneas.

\section{Estimativa da idade das águas subterrâneas}

O tempo de residência da água subterrânea em um aquífero é o período decorrido entre recarga e descarga de águas subterrâneas fluindo no sistema. Difere da idade da água subterrânea, que é o tempo decorrido desde a recarga das águas subterrâneas em trânsito em dado momento e local (Loáiciga, 2004). A idade é determinada com a datação isotópica. Portanto, estimativas da idade das águas subterrâneas da região foram realizadas por meio de análises de carbono-14 $\left({ }^{14} \mathrm{C}\right)$, trítio $\left({ }^{3} \mathrm{H}\right)$ e cloro-36 $\left({ }^{36} \mathrm{Cl}\right)$. Com as análises de $\delta^{13} \mathrm{C}\left({ }^{13} \mathrm{C} /{ }^{12} \mathrm{C}\right)$ estimou-se o percentual de dissolução de "carbonatos antigos" da rocha e realizou-se a correção da idade absoluta, através do modelo de Pearson (1965).

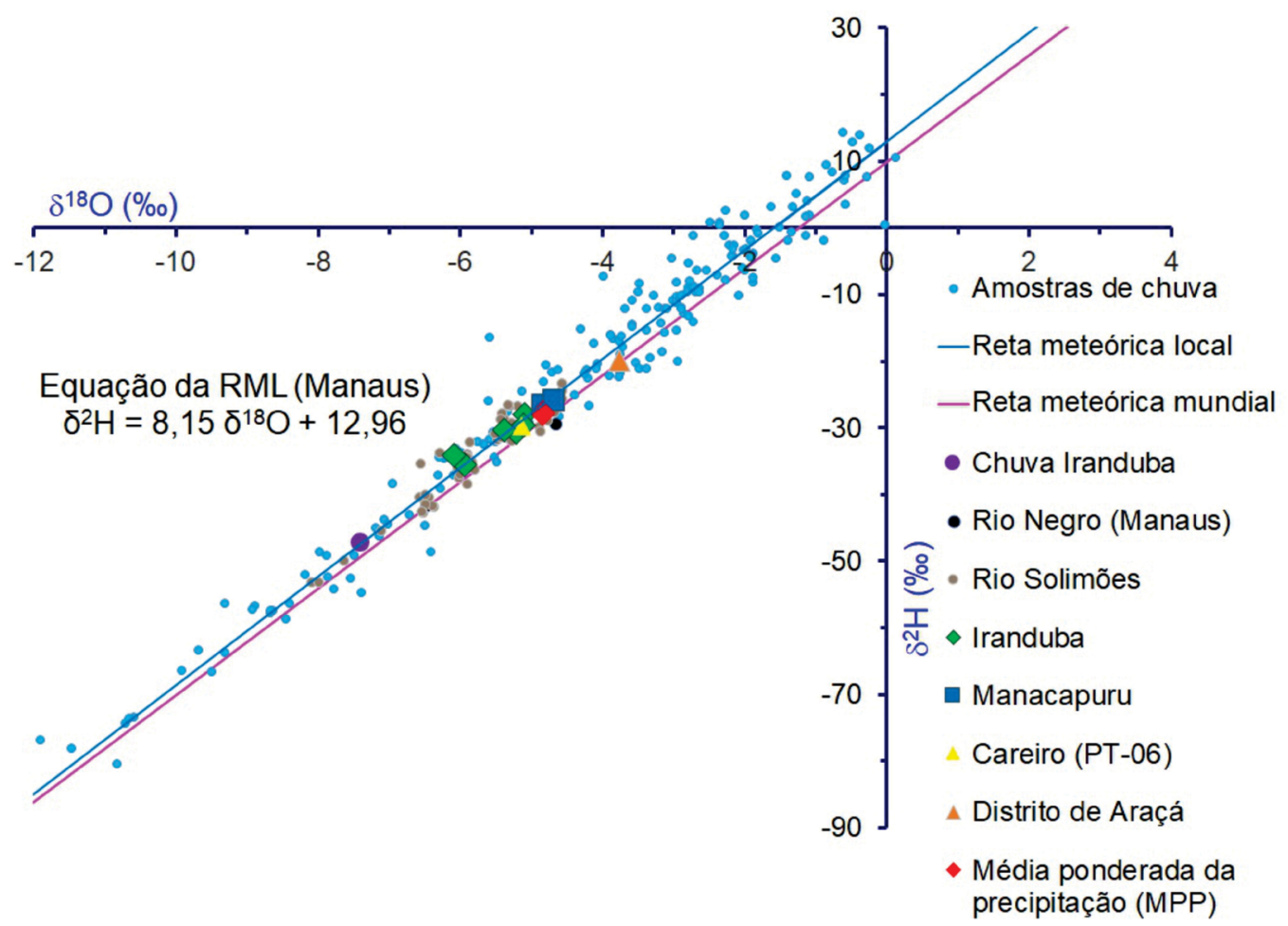

RML: reta meteórica local.

Figura 7. Gráfico da distribuição de $\delta^{2} \mathrm{H}$ e $\delta^{18} \mathrm{O}$ das amostras coletadas, juntamente com amostras de chuva e as retas meteóricas mundial e local da região de Manaus. 
Apesar de não terem sido realizadas datações em amostras de poços rasos, os dados da Tabela 2 sugerem a hipótese de águas com maior tempo de residência em profundidade no aquífero. As idades calibradas obtidas pelo método do ${ }^{14} \mathrm{C}$ nos poços com filtros mais profundos e maiores profundidades finais (Correnteza e Araçá) indicaram um valor médio de 20.381 anos, bem semelhante entre as duas amostras analisadas. Esse dado, aliado à semelhança química dessas amostras, indica tratar-se provavelmente do mesmo horizonte aquífero. A idade obtida permite classificar como paleoáguas as águas subterrâneas mais profundas e mineralizadas da região, obtidas nos poços de Manacapuru e Careiro.

No entanto, as amostras dos poços SAAE PT 07 e SAAE PT 09, do município de Iranduba, apresentaram idades máximas de 4500 anos e idades corrigidas e calibradas da ordem de 2000 anos. Em princípio, estes resultados não estariam de acordo com o fluxo regional esperado, já que áreas que se encontram mais a leste apresentaram idades menores.

Interpreta-se que as idades mais recentes obtidas estejam ligadas ao alto índice de recarga do aquífero em suas porções livres e aflorantes, como ocorre na região de Iranduba, e também à menor profundidade dos poços em Iranduba, com a presença de filtros em camadas mais rasas (entre 30 e $40 \mathrm{~m}$ ). Em Manacapuru, no entanto, os filtros começam a cerca de $80 \mathrm{~m}$ de profundidade. É provável que exista mescla de águas nessa região, com uma grande proporção de águas de recarga se infiltrando rapidamente nos níveis aquíferos mais profundos. Reforçam essa hipótese a provável presença de falhas condutoras e a ausência de uma camada selante entre os horizontes rasos e os mais profundos da FAC.
Além disso, o resultado da análise de ${ }^{3} \mathrm{H}$ realizada na amostra SAAE 01 demonstra existir, ainda que em pequena proporção, um componente de água recente no poço amostrado. A existência de filtros em horizontes rasos pode ser um dos fatores responsáveis por esse resultado. Concentrações de nitrato elevadas nessa amostra também indicam a presença de águas rasas, com indícios relevantes de contaminação antrópica. Isto pode ocorrer por defeitos na estrutura do poço. Assim, a análise de trítio sugere apenas que o tempo de trânsito pelas zonas não saturada e saturada foi maior que 50 anos, ao menos. É importante ressaltar que o erro analítico associado de 0,4 UT pode ser relevante nessa análise.

Os dados de $\delta^{13} \mathrm{C}$ apontaram para pouco fracionamento por dissolução de carbonatos da matriz aquífera. $\mathrm{O}$ valor de $\delta^{13} \mathrm{C}=-25 \%$ na água subterrânea de recarga, com a vegetação predominante do ciclo $\mathrm{C} 3$, sugere pouca influência destas fontes. Também é possível afirmar que há pouca influência de quaisquer águas superficiais nos poços Correnteza e distrito de Araçá, pois essas águas apresentam valores pouco depletados em $\delta^{13} \mathrm{C}$, cerca de $-8 \%$, segundo Bauer et al. (2005). Nos poços SAAE 01, 07 e 09, o $\delta^{13} \mathrm{C}$ é menos depletado, sugerindo processos de interação com carbonatos ou outros minerais antigos ao longo da evolução geoquímica da água no sistema. Esse valor também pode indicar maior mistura com águas meteóricas ou superficiais, que apresentam $\delta^{13} \mathrm{C}$ em equilíbrio com a atmosfera.

Na Tabela 3 são apresentados os parâmetros utilizados e o resultado da datação a partir do isótopo ${ }^{36} \mathrm{Cl}$. A concentração de $\mathrm{Cl}^{-}$inicial foi estimada em $0,92 \mathrm{mg} / \mathrm{L}$, com base

Tabela 2. Resultados de análises de ${ }^{14} \mathrm{C},{ }^{3} \mathrm{H}$ e $\delta^{13} \mathrm{C}$ nas amostras do aquífero Sistema Aquífero Alter do Chão.

\begin{tabular}{|c|c|c|c|c|c|c|c|}
\hline Amostra & $\begin{array}{l}\text { Profundidade média } \\
\text { dos filtros }(\mathrm{m})\end{array}$ & $\begin{array}{c}\text { Atividade } \\
\text { de }{ }^{14} \mathrm{C} \\
(\mathrm{pmC})\end{array}$ & $\delta^{13} \mathrm{C}(\%)$ & ${ }^{3} \mathrm{H}(\mathrm{UT})$ & $\begin{array}{c}\text { Idade não } \\
\text { corrigida } \\
\text { por }{ }^{14} \mathrm{C} \\
\end{array}$ & $\begin{array}{c}\text { Idade } \\
\text { corrigida } \\
\text { de }{ }^{14} \mathrm{C} \\
\end{array}$ & $\begin{array}{c}\text { Idade } \\
\text { calibrada } \\
\text { de }{ }^{14} \mathrm{C} \\
\end{array}$ \\
\hline Correnteza & $\begin{array}{c}\text { 78; 104; 118; 136; } \\
\text { 150; 168; 194; } \\
214 \mathrm{~m}\end{array}$ & $12,14 \pm 0,12$ & $-19,7$ & - & $16939 \pm 79$ & $15695 \pm 79$ & $18937 \pm 79$ \\
\hline Distrito de Araçá & Indisponível & $10,2 \pm 0,2$ & $-22,1$ & - & $18338 \pm 159$ & $18017 \pm 159$ & $21826 \pm 159$ \\
\hline SAAE PT 07 & $\begin{array}{c}\text { 36; 52; 70; 78; 88; } \\
\text { 114; 126; } 142 \text { m }\end{array}$ & $59,2 \pm 0,2$ & $-16,9$ & - & $4211 \pm 27$ & $1736 \pm 27$ & $1651 \pm 28$ \\
\hline SAAE PT 09 & 44; 67; 82 até 139 m & $57,1 \pm 0,2$ & $-17,7$ & - & $4501 \pm 28$ & $2397 \pm 28$ & $2416 \pm 28$ \\
\hline SAAE PT 01 & $\begin{array}{c}38 ; 46 ; 56 ; 68 ; 82 ; \\
89 ; 114 ; 126 ; 142 \text { m }\end{array}$ & n.d. & $-12,1$ & $0,9 \pm 0,4$ & - & - & - \\
\hline
\end{tabular}

n.d.: não foi possível detectar, pois o conteúdo de carbono inorgânico total é muito baixo.

Tabela 3. Resultados da análise isotópica de ${ }^{36} \mathrm{Cl}$ na amostra de água do poço Correnteza (Manacapuru-AM).

\begin{tabular}{lccccc}
\hline Amostra & $\mathbf{R}_{36}\left({ }^{36} \mathrm{Cl} / \mathrm{Cl}\right)$ medida & $\begin{array}{c}\mathbf{R}_{36}\left({ }^{36} \mathrm{Cl} / \mathrm{Cl}\right) \\
\text { estimada na } \\
\text { recarga }\end{array}$ & $\begin{array}{c}\text { Razão de } \\
\text { equilíbrio do } \\
\text { aquífero }\left(\mathbf{R}_{\mathrm{se}}\right)\end{array}$ & $\begin{array}{c}\text { Idade obtida com } \\
\mathbf{R}_{\mathrm{se}} \text { do aquífero }\end{array}$ & $\begin{array}{c}\text { Idade corrigida } \\
\text { para dissolução } \\
\text { de halita }\left(\mathbf{R}_{\mathrm{se}}=0\right)\end{array}$ \\
\hline Correnteza & $14,16 \pm 2,69 \times 10^{-15}$ & $300 \times 10^{-15}$ & $5 \times 10^{-15}$ & $633,4 \pm 151 \mathrm{ka}$ & $451,6 \pm 91 \mathrm{ka}$ \\
\hline
\end{tabular}


na média de $\mathrm{Cl}^{-}$nas amostras diluídas da região. O resultado indicou um tempo de residência da ordem de 633,3 a 451,56 ka para a amostra do poço Correnteza, valor bem superior à estimativa realizada com os isótopos de ${ }^{14} \mathrm{C}$. Além da imprecisão decorrente do baixo conteúdo de $\mathrm{Cl}$, a maior parte do cloreto do aquífero em Manacapuru é proveniente da mescla com águas subterrâneas consideravelmente mais antigas, passando de 1 a $2 \mathrm{mg} / \mathrm{L}$, na recarga, para 5 a $10 \mathrm{mg} / \mathrm{L}$. Ressalte-se que uma pequena contribuição de uma solução muito mais salina em contato com águas mais diluídas poderia resultar na água observada na região, pois mesmo concentrações baixas podem ser dominadas pelo cloreto de outras fontes que não as atmosféricas (IAEA, 2013).

Dessa forma, a idade estimada pelo modelo de ${ }^{36} \mathrm{Cl}$ é imprecisa. Fluxos regionais mais salinos ao longo da bacia sedimentar são o fator mais provável para explicar o resultado.

Em suma, revela-se, a partir dos dados isotópicos, que tanto a expressiva recarga ao aquífero em suas porções livres e aflorantes quanto a provável comunicação com suas porções mais profundas por descontinuidades podem concorrer para a mistura de águas jovens com águas mais antigas da porção inferior do aquífero. Essa comunicação também poderia ocorrer pela ausência de camadas impermeáveis contínuas na Bacia do Amazonas.

A água subterrânea, nas camadas mais profundas, foi, portanto, recarregada há muito tempo e renova-se muito lentamente em escalas humanas, devendo ser utilizada com racionalidade. No entanto, o aquífero vem sendo consideravelmente explotado nos últimos anos, principalmente em cidades que experimentaram um elevado crescimento populacional, como Iranduba e Manacapuru. Nesses dois municípios, a comparação de dados históricos do nível estático nos poços profundos de abastecimento público desde 2001 até os dias de hoje, realizada a partir de dados da plataforma SIAGAS/ CPRM, revelam que os níveis piezométricos encontram-se depletados atualmente em cerca de $15 \mathrm{~m}$, podendo chegar a 20 ou $30 \mathrm{~m}$ em alguns pontos, um rebaixamento significativo nas áreas urbanas. Efeito semelhante foi observado em Manaus por Aguiar (2012). Isso pode provocar consequências indesejáveis, como a contaminação dos recursos por águas rasas influenciadas pela atividade antrópica e a inversão de fluxo subterrâneo em alguns locais, prejudicando os ecossistemas superficiais, salinizando e diminuindo a disponibilidade hídrica no sistema.

\section{Teste de hipóteses conceituais com simulações através do código PHREEQCI}

Com o auxílio da ferramenta numérica PHREEQCI 3.3.7 obtiveram-se os índices de saturação dos minerais presentes nas soluções e, com uma abordagem de simulação direta, realizaram-se testes das hipóteses conceituais apresentadas anteriormente com o módulo MIX.
Índices de saturação

Os índices de saturação (IS) dos minerais mais relevantes presentes nas águas estudadas são apresentados na Figura 8. Os valores de IS positivos indicam supersaturação dos minerais e tendência à precipitação, enquanto os índices negativos indicam subsaturação e tendência à dissolução. IS igual a zero indica equilíbrio, porém valores entre $-0,5$ e 0,5 são considerados como na faixa de equilíbrio devido aos erros associados às análises (Appelo e Postma, 2005).

Em relação aos minerais carbonáticos, a maioria das águas subterrâneas na área de estudo apresenta-se subsaturada a próxima do equilíbrio. A única exceção foi o poço do Porto de Iranduba, onde as amostras apresentaram-se levemente supersaturadas em carbonatos de ferro devido aos índices elevados de $\mathrm{Mn}$ e Fe na água, produzidos pelos processos biológicos típicos da região de várzea amazônica.

Nas amostras bicarbonatadas mais mineralizadas, de Manacapuru e do distrito de Araçá em Careiro, observou-se maior proximidade ao equilíbrio em minerais carbonáticos, como calcita, aragonita e siderita. Apenas a siderita é registrada como mineral traço da $\mathrm{FAC}$, na região de Urucu (Petrobras, 2009). Águas que circularam por outras formações (Fm. Nova Olinda) ou a cimentação carbonática dos arenitos da FAC em seus níveis mais profundos (ainda não registrada na região) poderiam explicar o fenômeno. Nas demais amostras ocorreram valores baixos do IS em carbonatos.

Quanto a minerais evaporíticos, como halita e silvita, as águas estão muito subsaturadas, (IS entre -6,65 e -12,37). Apenas as amostras cloretadas de Iranduba e Manaquiri têm maiores índices de saturação, indicando baixa relevância de processos de dissolução de minerais evaporíticos, conforme sugerido pelas razões $\mathrm{rCl}^{-} / \mathrm{rBr}$. Estes minerais são muito solúveis, e sua dissolução levaria à rápida elevação dos IS. Assim, o conjunto dos dados sugere pouca significância da solubilização de evaporitos no aquífero. Ganha força, portanto, a hipótese de mescla com águas cloretadas provenientes de um fluxo regional pelo Sistema Aquífero Amazônico (SAA), em detrimento da possibilidade de contato com águas de formações evaporíticas (Fm. Nova Olinda).

Quanto aos argilominerais e minerais silicáticos, as águas subterrâneas apresentam-se saturadas em caulinita, mica potássica (muscovita) e montmorillonita cálcica em quase toda a área. Esses minerais são registrados em estudos mineralógicos da FAC na região (RADAMBRASIL, 1978). Algumas amostras mais diluídas (PT-06/Careiro e INPA) apresentaram-se subsaturadas com relação a esses minerais, reforçando a hipótese de recarga recente e pouco tempo de interação com o substrato rochoso.

A série do plagioclásio encontra-se subsaturada na área de estudo. A alta estabilidade dos silicatos e seu lento processo de 
A

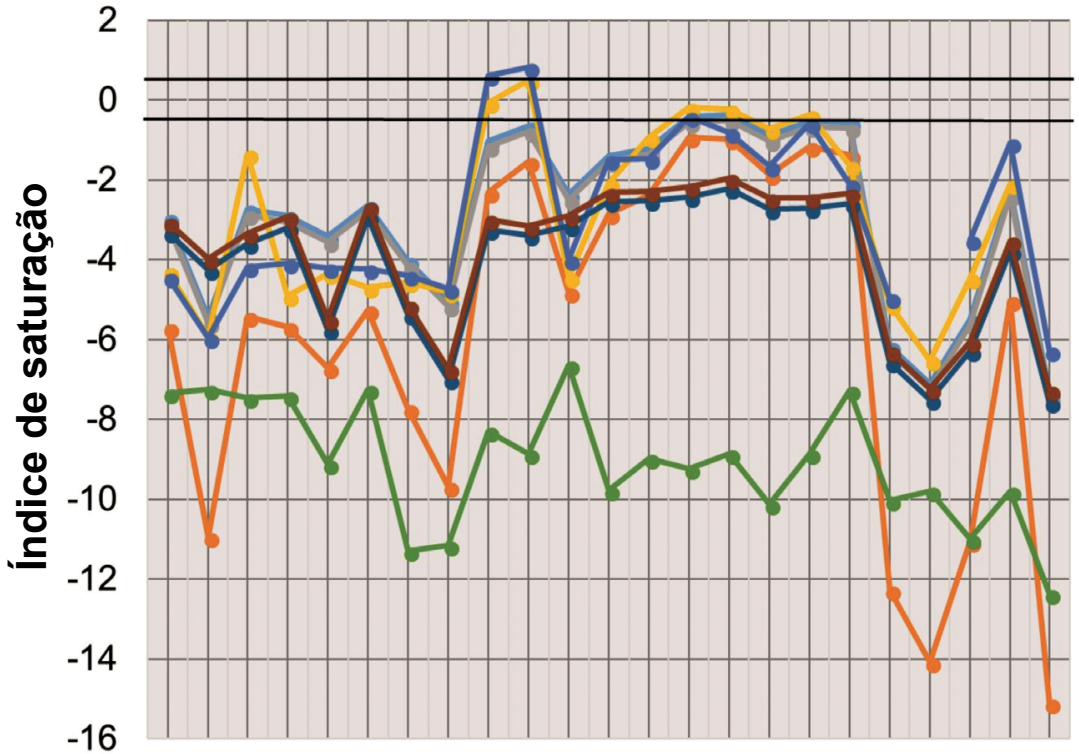

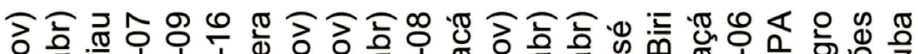

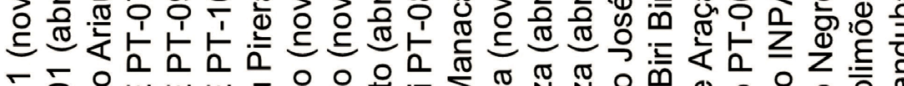

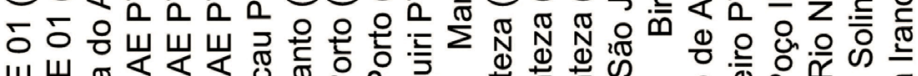

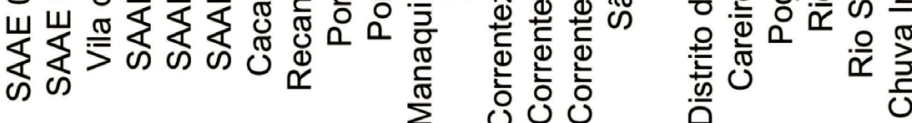

$\rightarrow$ Calcita

Dolomita

-Aragonita

-Rodocrosita

Siderita

$\sim$ Halita

$\rightarrow-$ Anidrita

$\multimap$ Gesso

-Zona de equilíbrio
B

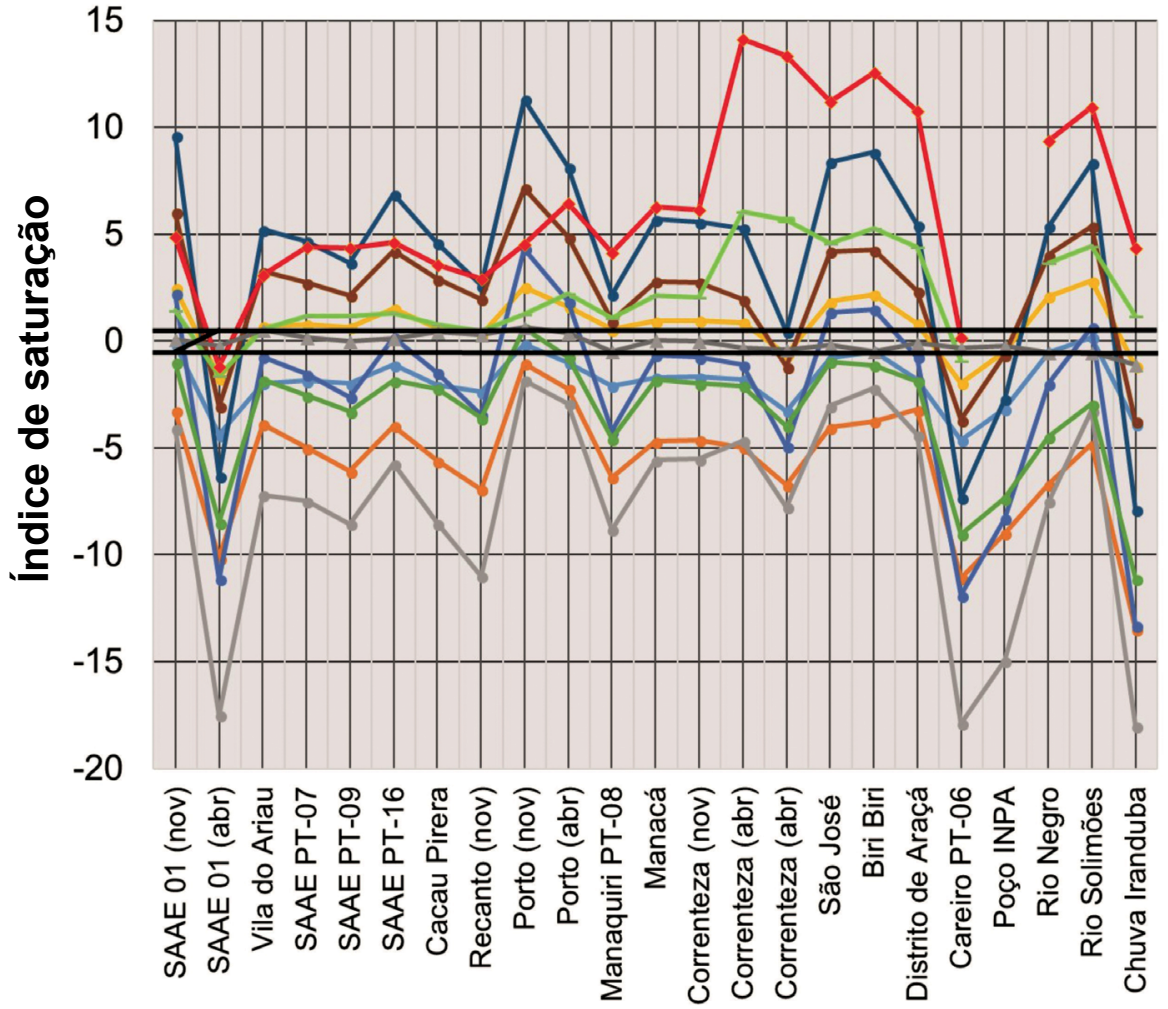

$\rightarrow \mathrm{Al}(\mathrm{OH}) 3(\mathrm{a})$

$\rightarrow$ Albita

$\rightarrow$-Anortita

- Gibbsita

$\rightarrow-$ llita

$\rightarrow$ K-feldspato

- K-mica

-Caulinita

- Goethita

$\rightarrow$ Hematita

-Quartzo

-Zona de equilíbrio

Figura 8. Índices de saturação dos minerais carbonáticos e evaporíticos $(A)$ e de argilominerais e minerais silicáticos (B) em amostras de água subterrânea da área de estudo. 
hidrólise respondem pelo fenômeno. Esses minerais reagem de forma tão lenta que o equilíbrio nunca é atingido a baixas temperaturas (Appelo e Postma, 2005). $\mathrm{Al}(\mathrm{OH})_{3}$ amorfo, ilita e K-feldspato apresentam-se em geral subsaturados, pelas mesmas razões. A ilita e o K-feldspato são minerais encontrados frequentemente na FAC aflorante.

A hematita apresentou-se sempre supersaturada, enquanto a gibbsita mostrou-se levemente supersaturada ou em equilíbrio, estando subsaturadas apenas nas amostras diluídas da área, devido ao menor tempo de contato com o substrato. Estes minerais são encontrados frequentemente nas rochas da FAC, principalmente nas camadas avermelhadas típicas da região de Manaus (Horbe et al., 2006). Assim, a observada supersaturação deve-se provavelmente à interação efetiva com tais minerais.

Em resumo, a análise dos IS aponta para a atuação de processos de intemperismo de silicatos e de argilominerais típicos do arcabouço da FAC na região. O processo de interação com carbonatos e evaporitos, caso ocorra, é pouco significativo ou mascarado por uma alta diluição por águas meteóricas. Devido à solubilidade elevada desses minerais, o equilíbrio tenderia a ser rapidamente atingido, levando à supersaturação (Zhu e Anderson, 2002).

\section{Modelo de mescla}

Utilizou-se o módulo MIX do programa PHREEQCI para avaliar a possibilidade da existência de mescla de águas recarregadas localmente com águas provenientes de fluxos regionais ao longo do grande SAA. As proporções de mescla foram estimadas a partir do modelo isotópico de Pearson (1965), adotado para a correção das idades de ${ }^{14} \mathrm{C}$, que indicou um percentual de 10 a $15 \%$ de "carbono antigo". Dessa forma, o exercício realizado utilizou percentuais de mescla de, respectivamente, $85 \%$ (MIX A) e $90 \%$ (MIX B) de água meteórica contra, respectivamente, 15 e $10 \%$ de água profunda.

Como dados de entrada ao modelo utilizaram-se a chuva local e dados de águas subterrâneas profundas da FAC (cerca de 500 a $600 \mathrm{~m}$ de profundidade), na Bacia do Solimões, a partir do trabalho de Rosário (2011). As análises dessa autora são as únicas disponíveis para intervalos unicamente profundos da $\mathrm{FAC}$, e não são balanceadas. Isto trouxe algumas limitações aos resultados, pois só foi

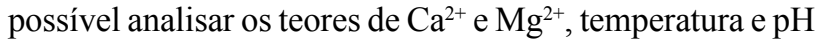
da solução resultante. Os dados de entrada e os resultados encontram-se na Tabela 4.

$\mathrm{O}$ resultado obtido para o íon $\mathrm{Ca}^{+2}$ ficou próximo do encontrado nas águas subterrâneas profundas de Manacapuru, principalmente no MIX 1A ( $85 \%$ de diluição), porém não muito distante dos valores que ocorrem em Iranduba. Já para o íon $\mathrm{Mg}^{2+}$, os valores encontrados foram maiores do que os observados nos poços. A salinidade das soluções resultantes foi muito semelhante no MIX 1A ao observado em Manacapuru. No MIX 1B (90\% de águas meteóricas), a salinidade não teve um bom ajuste devido ao caráter incompleto da análise utilizada, pois, por exemplo, o $\mathrm{Cl}^{-}$(ausente na análise) tem concentração elevada nas águas subterrâneas em Iranduba e Manaquiri. O resultado do MIX 2B (90\% de águas meteóricas com a solução inicial 2), porém, ajustou-se satisfatoriamente aos teores de $\mathrm{Ca}^{2+} \mathrm{e} \mathrm{Mg}^{2+}$ observados nos poços de Iranduba e Manaquiri. Essas observações podem sugerir proporções diferentes de diluição nessas duas localidades, possivelmente devido à menor profundidade dos poços na região de Iranduba ou a outros fatores não avaliados.

De forma geral, considerou-se que a mescla de águas de circulação regional com águas meteóricas abundantes, provocando grande diluição, é geoquimicamente factível na área de estudo e poderia responder pelo comportamento das águas subterrâneas observadas nos horizontes aquíferos

Tabela 4. Dados de entrada e resultados do modelo de mescla calculado com o programa PHREEQCl. As soluções resultantes foram denominadas 1A, 1B, 2A e 2B, de acordo com a solução inicial (amostras 1 ou 2) e a proporção de mistura $(A=85 \% / 15 \%$ e $B=90 \% / 10 \%)$.

\begin{tabular}{lccccc}
\hline Solução & $\mathbf{p H}$ & $\begin{array}{c}\text { Temperatura } \\
\left({ }^{\circ} \mathbf{C}\right)\end{array}$ & $\begin{array}{c}\text { Salinidade } \\
\text { total }(\mathbf{m g} / \mathbf{L})\end{array}$ & $\mathbf{C a}(\mathbf{m g} / \mathbf{L})$ & $\mathbf{M g}(\mathbf{m g} / \mathbf{L})$ \\
\hline Chuva local & 4,85 & 24,3 & 12,3 & 0,082 & 0,013 \\
Água subterrânea profunda 1 & 6,5 & 61 & 5330 & 200 & 315 \\
Água subterrânea profunda 2 & 7,1 & 40 & 7425 & 200 & 145 \\
MIX 1A (85\% chuva + 15\% amostra 1) & 4,85 & 29,8 & 192 & 30,02 & 47,07 \\
MIX 1B (90\% chuva/10\% amostra 1) & 4,85 & 28 & 127 & 20,04 & 31,39 \\
MIX 2A (85\% chuva + 15\% amostra 2) & 4,86 & 26,6 & 116 & 30,02 & 21,67 \\
MIX 2B (90\% chuva + 10\% amostra 2) & 4,86 & 25,9 & 79 & 20,04 & 14,45 \\
Água média - Manacapuru/distrito Araçá & 6,89 & 29,5 & 200,5 & 32,06 & 9,93 \\
Água média - Iranduba/Manaquiri & 5,25 & 28,3 & 265,9 & 24,64 & 11,52 \\
\hline
\end{tabular}


mais profundos. Para que o modelo se adequasse melhor, um ajuste mais fino na solução de entrada seria necessário, o que não foi possível devido à limitação de dados atual. Entretanto, isso poderá ser realizado em estudos futuros, diante da disponibilidade de novos dados.

\section{Modelo hidrogeológico conceitual}

A compilação dos dados disponíveis permitiu a elaboração de uma seção hidrogeológica esquemática da área de estudo e de regiões adjacentes a oeste, que constitui a síntese do modelo hidrogeológico conceitual (Figura 9). Na região de Iranduba e Manacapuru, onde o AAC aflora desde o longo confinamento a oeste, ocorrem camadas predominantemente arenosas, com poucas intercalações de argila, delimitando um aquífero livre de bom potencial, até profundidades de cerca de $120 \mathrm{~m}$. As águas nestes horizontes são bastante diluídas e invariavelmente ácidas (Tabela 1), oscilando entre bicarbonatadas-cálcicas (magnesianas) e cloretadas-sódicas (Figura 3). Neles, estão as seções filtrantes da maioria dos poços tubulares utilizados para o abastecimento de água na região, inclusive os mais profundos. Segundo o modelo aqui proposto, as águas originam-se por recarga local com a chuva e a rápida infiltração no aquífero, bastante permeável e poroso. As águas são constantemente renovadas com o alto índice pluviométrico da região. Essa porção superior do AAC é bem registrada na literatura, com essas mesmas características, principalmente na região de Manaus (Aguiar, 2012). A partir dos dados estratigráficos de poços de petróleo e de água existentes, este aquífero se estende a ocidente, com tais características, possivelmente até a região de Codajás.

A oeste de Manacapuru e na margem direita do rio Solimões, de acordo com os mapas geológicos disponíveis (CPRM, 2006; IBGE, 2011), afloram os depósitos mais recentes da Formação Içá. Nessa formação, há uma ocorrência maior de arenitos em relação à FS, e os seus depósitos são

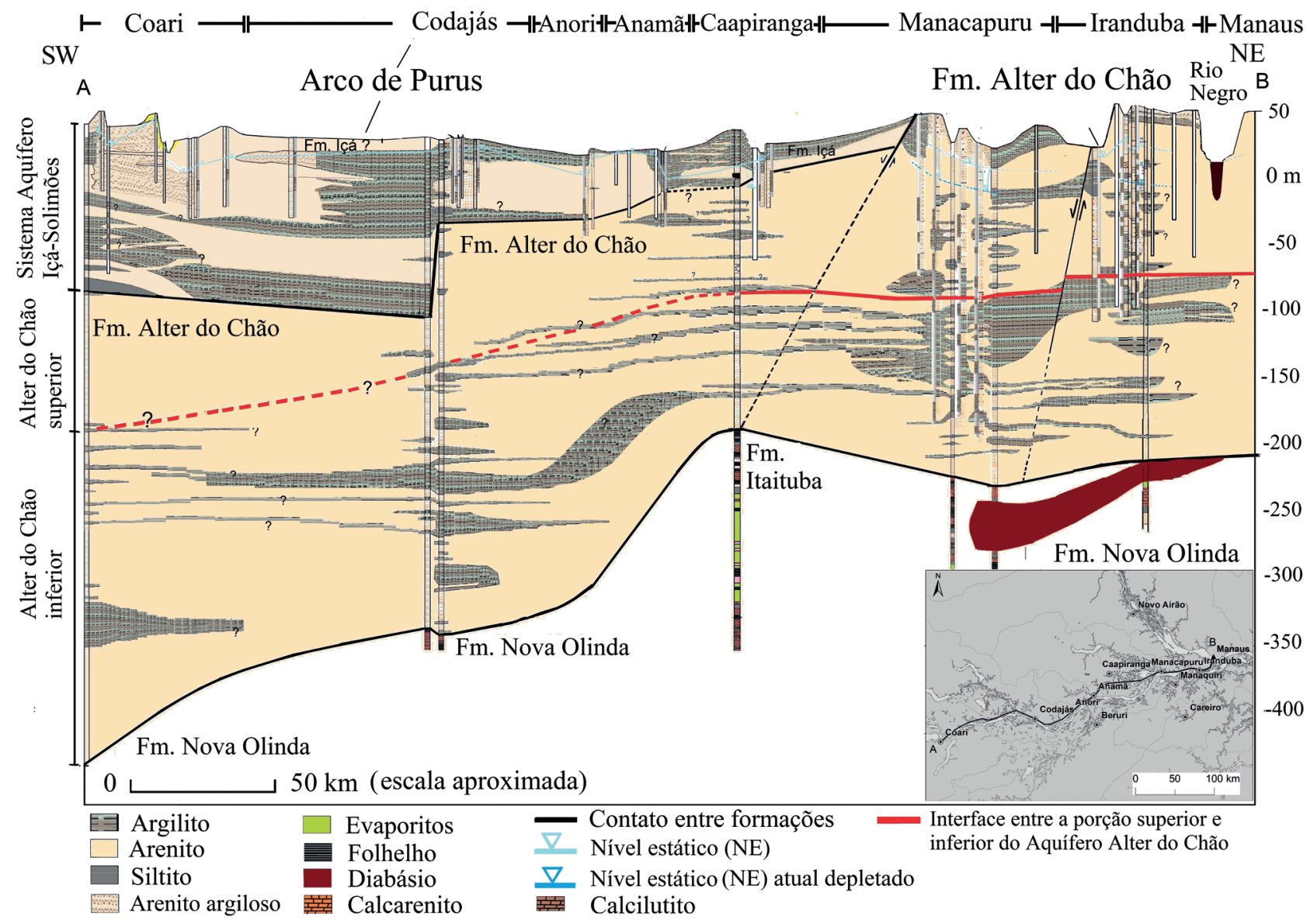

Figura 9. Seção hidrogeológica esquemática da área de estudo, situada a oeste de Manaus, na margem esquerda do rio Solimões. Foram integrados os dados litológicos, estratigráficos, hidrogeológicos e hidrogeoquímicos de poços de água e de petróleo nessa região. 
pouco espessos, raramente superando os $50 \mathrm{~m}$, de acordo com os dados consultados (Figura 9). Dessa forma, os poços mais rasos, a oeste de Manacapuru e na margem direita do rio Solimões, provavelmente explotam os aquíferos da Formação Içá ou os níveis superiores da FAC. Assim como observado por Souza et al. (2013), notou-se que as águas da Formação Içá têm características similares às da camada superior do AAC. São águas bastante diluídas (CE inferior a $100 \mu \mathrm{S} . \mathrm{cm}^{-1}$ ), geralmente bicarbonatadas sódicas (secundariamente potássicas e também cálcicas), originadas de recarga recente a partir da precipitação. É possível a existência de conexão hidráulica entre esses aquíferos ou, até mesmo, que constituam o mesmo aquífero, o que, todavia, não pôde ser determinado neste estudo.

A partir da região de Codajás, nas proximidades do Arco de Purus, a Formação Içá grada lateralmente para a FS em direção oeste, tornando-se mais argilosa e espessa, chegando a cerca de $120 \mathrm{~m}$ de profundidade na região urbana de Coari. Na Bacia do Solimões ela fica ainda mais espessa, e os poços existentes já não acessam a FAC. Assim, não se dispõe de dados hidroquímicos, exceto na base petrolífera de Urucu, onde a salinidade é muito mais elevada, com concentrações em torno de 7 a 8 g/L (Rosário et al., 2016; Souza et al., 2015). Mais a oeste, na parte central da Bacia do Solimões, distante a oeste da área de estudo, explotam-se os aquíferos associados à FS, que possui níveis mais arenosos no topo e espessas camadas de argila na base, formando um aquitardo, com 160 m de espessura média, que muito provavelmente isola a FAC de qualquer interação com a superfície (Galvão et al., 2012).

$\mathrm{Na}$ região de Iranduba e Manacapuru, bem como em alguns poços do município de Careiro e Manaquiri, a partir dos 120 a $130 \mathrm{~m}$ de profundidade, geralmente ocorrem horizontes com águas mais mineralizadas (CE superior a $250 \mu \mathrm{S} . \mathrm{cm}^{-1}$ ), de características bicarbonatadas-cálcicas (magnesianas), sódicas (Manacapuru e Careiro) ou cloretadas-cálcicas (magnesianas) (Iranduba e Manaquiri). $\mathrm{O}$ pH varia de ácido a levemente básico. As datações por ${ }^{14} \mathrm{C}$ realizadas indicam que as águas desse sistema se originam de processos mais prolongados de interação água-rocha, circulando de forma mais lenta, possivelmente por distâncias mais longas dentro dos aquíferos. Embora alguns estudos considerem a possível influência dos evaporitos e calcários da Fm. Nova Olinda na salinidade dessas águas, os dados químicos apresentados no presente trabalho sugerem que há pouca contribuição direta da dissolução desses minerais. Esta seria a porção inferior do AAC na área de estudo.

A separação física entre os horizontes aquíferos explotados e o topo da Fm. Nova Olinda é relativamente grande, podendo chegar a mais de $50 \mathrm{~m}$ de espessura de sedimentos. Além disso, a configuração geológica da FAC em seus níveis inferiores é pouco permeável, sugerindo baixa ou nula conexão com os aquíferos da Fm. Nova Olinda. A gradação a níveis mais argilosos na base do AAC é recorrente ao longo da porção oeste da Bacia do Amazonas, sugerindo uma deposição em um sistema de menor energia. Observação semelhante foi feita por Mendes (2010) em estudos sedimentológicos desenvolvidos na FAC, na região de Óbidos (PA). Essa porção inferior do AAC não pôde ter sua região de interface com a FS determinada com precisão, a oeste, pela ausência de poços profundos com informações hidroquímicas e hidrogeológicas nessa região.

As simulações geoquímicas realizadas mostraram ser factível a ocorrência de mescla de águas altamente mineralizadas, de origem remota, recarregadas nas regiões distantes do SAA, a oeste, com águas mais diluídas recarregadas localmente, respondendo pela composição das águas subterrâneas mais mineralizadas observadas na região do estudo.

\section{CONCLUSÕES}

As águas do AAC a oeste de Manaus possuem duas origens principais: meteórica, sendo provenientes de recarga a partir da precipitação pluviométrica, pouco mineralizadas e armazenadas nas camadas aquíferas superiores (até cerca de 120 a $130 \mathrm{~m}$ de profundidade), em um sistema aquífero predominantemente livre; e domínio de rocha, sendo caracterizadas por maior mineralização devido ao maior tempo de residência no aquífero e a um processo de interação água-rocha mais desenvolvido. Essas águas estão armazenadas, geralmente, nas camadas aquíferas mais profundas (mais de $130 \mathrm{~m}$ de profundidade), sob condições de confinamento ou semiconfinamento. Sua salinidade tende a aumentar com a profundidade. Por conta dessa diferenciação das águas subterrâneas, com origens hidrogeoquímicas distintas, que está correlacionada com a geologia local, propõe-se a divisão hidrogeoquímica do AAC em um sistema superior (até aproximadamente $130 \mathrm{~m}$ de profundidade) e um inferior (abaixo de $130 \mathrm{~m}$ de profundidade).

Em alguns locais, fatores como estruturas geológicas ou variações faciológicas/estratigráficas alteram esta configuração, conforme observado em alguns poços. Estes fatores podem causar mistura das águas e/ou processos de recarga do aquífero confinado por águas meteóricas mais jovens. Isso, associado ao fato de os poços selecionados para o estudo geoquímico possuírem, por vezes, perfis construtivos com filtros em profundidades mais rasas, dificulta a interpretação hidrogeoquímica.

O processo de intemperismo de silicatos pode ser considerado dominante na gênese do caráter hidrogeoquímico do AAC. Local e secundariamente, fenômenos de troca iônica, dissolução de sais e de carbonatos podem afetar a composição química das águas. Isto pode se dever à influência da Formação Nova Olinda, por meio de reações com os evaporitos e carbonatos associados a essa formação. 
No entanto, as razões iônicas e os IS calculados não indicaram uma clara evidência desses processos nas águas mais mineralizadas.

Os dados isotópicos de ${ }^{14} \mathrm{C}$ confirmaram a hipótese da existência de águas com maior idade em maiores profundidades no aquífero, apesar de não ter sido realizada datação nos horizontes superiores, pois estes indicam claramente origem meteórica recente. A idade média observada em duas amostras obtidas foi de 21,38 ka, desde o isolamento da atmosfera. A semelhança na fácies hidrogeoquímica e nas idades obtidas nos dois pontos sugere águas pertencentes ao mesmo aquífero, com origens semelhantes. A datação por ${ }^{36} \mathrm{Cl}$ apontou idade de pelo menos 451 ka para a amostra do poço Correnteza (Manacapuru). Interpreta-se que a maior parte do cloreto presente na amostra seja proveniente de fontes antigas e profundas e não de fontes atmosféricas, e que o resultado obtido revele a possível idade destas fontes. A água, portanto, seria originada provavelmente da mescla de certa quantidade de águas meteóricas com uma proporção menor de águas de circulação regional nos aquíferos amazônicos. O cálculo geoquímico preliminar realizado com o programa PHREEQCI revelou coerência para essa hipótese na região.

Dessa forma, os dados revelam que as camadas mais profundas da FAC (Aquífero Alter do Chão Inferior) constituem um recurso hídrico que demanda longo tempo para sua constituição e renovação e que, por isso, deve ser utilizado com racionalidade. Dados disponíveis no sistema SIAGAS indicam que os níveis estáticos atuais se encontram depletados em pelo menos $15 \mathrm{~m}$ nas áreas urbanas de Iranduba e Manacapuru comparados aos níveis pré-explotação. Recomenda-se que estudos sejam desenvolvidos para avaliar a real dimensão deste efeito na região, considerando, por exemplo, a sazonalidade e outros fatores.

A explotação excessiva e indiscriminada do aquífero observada na região pode levar a efeitos indesejáveis, como a alteração do fluxo subterrâneo natural e a degradação dos recursos hídricos por águas superficiais contaminadas ou águas salinizadas mais profundas. Tal fato tem sido verificado em alguns poços tubulares, que apresentam altas concentrações de nitrato. É necessário que os órgãos públicos estabeleçam programas para uma gestão adequada do recurso hídrico subterrâneo, que se apresenta vulnerável na região.

\section{AGRADECIMENTOS}

À PETROBRAS pelo fornecimento de dados e financiamento das pesquisas por meio do fundo de participação especial ANP, o que viabilizou a realização das campanhas de campo e das análises laboratoriais. À Coordenação de Aperfeiçoamento de Pessoal de Nível Superior (CAPES) e ao Conselho Nacional de Desenvolvimento Científico e
Tecnológico (CNPq) pela concessão de bolsas e recursos para a pesquisa na região.

\section{REFERÊNCIAS}

Abreu, F. A. M., Cavalvante, I. N., Matta, M. A. S. (2013). O sistema aquífero grande Amazônia - SAGA: um imenso potencial de água subterrânea no Brasil. III Congresso Internacional de Meio Ambiente Subterrâneo. São Paulo: ABAS.

Agência Nacional de Águas - ANA. (2005). Panorama da qualidade das águas subterrâneas no Brasil. Brasília: ANA. 80 p.

Agência Nacional do Petróleo, Gás Natural e Biocombustíveis - ANP. (2015). Bacia do Amazonas: Sumário Geológico e Setores em Oferta. Brasília: ANP.

Aguiar, C. J. B. (2012). Relatório diagnóstico Aquífero Alter do Chão no Estado do Amazonas, Bacia Sedimentar do Amazonas. In: C. J. B. Aguiar, M. A. A. Mourão (Eds.), Projeto Rede Integrada de Monitoramento das Águas Subterrâneas. Belo Horizonte: CPRM - Serviço Geológico do Brasil. (Coleção de Relatórios-Diagnóstico dos Aquíferos Sedimentares do Brasil).

Aguiar, C. B. J., Marmos, J. L. (2010). Principais aquíferos do estado do Amazonas e qualidade de suas águas. In: M. A. M. Maia, J. L. Marmos (Eds.), Geodiversidade do Estado do Amazonas. Manaus: CPRM - Serviço Geológico do Brasil. (Programa Geologia do Brasil: Levantamento da Geodiversidade).

Alcalá, F. J., Custodio, E. (2008). Using the $\mathrm{Cl} / \mathrm{Br}$ ratio as a tracer to identify the origin of salinity in aquifers in Spain and Portugal. Journal of Hydrology, 359(1-2), 189-207. https://doi.org/10.1016/j.jhydrol.2008.06.028

Appelo, C. A. J., Postma, D. (2005). Geochemistry, groundwater and pollution. Amsterdam: Balkema.

Azevedo, R. P. (2006). Uso de água subterrânea em sistema de abastecimento público de comunidades na várzea da Amazônia central. Acta Amazonica, 36(3), 313-320. http:// dx.doi.org/10.1590/S0044-59672006000300004

Bauer, M., Einchinger, L., Elsass, P., Kloppmann, W., Wirsing, G. (2005). Isotopic and hydrochemical studies of groundwater flow and salinity in the Southern Upper Rhine Graben. International Journal of Earth Sciences (Geol Rundsch), 94(4), 565-579. http://dx.doi.org/10.1007/s00531-005-0500-5 
Beato, D. A. C., Oliveira, F. A. R., Viana, H. S. (1999). Estudos geoambientais das fontes hidrominerais de Águas de Contendas, Cambuqueira, Caxambu, Lambari e São Lourenço. Belo Horizonte: Secretaria de Estado de Minas e Energia. 142 p.

Bentley, H. W., Phillips, F. M., Davis, S. N. (1986). Chlorine-36 in the terrestrial environment. In: P. Fritz, J. C. Fontes (Eds.). Handbook of Environmental Isotope Geochemistry: The Terrestrial Environment (v. 2, 427-480). Amsterdam: B. Elsevier.

Bozdag, A., Göçmez, G. (2016). Hydrogeochemical and Isotopic Study of Groundwater in a Semi-arid Region: Yeniceoba Plain (Cihanbeyli-Konya), Central Anatolia, Turkey. Acta Geologica Sinica, 90(1), 230-241. https://doi. org/10.1111/1755-6724.12654

Caputo, M. V. (1984). Stratigraphy, tectonics, paleoclimatology and paleogeography of northern basins of Brazil. Tese (Doutorado). Califórnia: Universidade da Califórnia.

Caputo, M. V. (2011). Discussão sobre a Formação Alter do Chão e o Alto de Monte Alegre. In: R. S. C. Nascimento, A. M. C. Horbe, C. M. Almeida (Eds.), Contribuições à Geologia da Amazônia (v. 7, 7-23). Manaus: SBG.

Clark, I. D., Fritz, P. (1997). Environmental isotopes in hydrogeology. Boca Raton, Florida: CRC Press.

Companhia de Pesquisa de Recursos Minerais - CPRM. (2006). Geologia e recursos Minerais do estado do Amazonas. Programa integração, atualização e difusão de dados da geologia do Brasil, subprograma mapas geológicos estaduais: mapa geológico e de recursos minerais do estado do Amazonas. Escala 1:1.000.000. Manaus: CPRM.

Companhia de Pesquisa de Recursos Minerais - CPRM. Sistema de Informações de Águas Subterrâneas (SIAGAS). Disponível em: <http://siagasweb.cprm.gov.br/layout>. Acesso em: 30 nov. 2017.

Corcóvia, J. A., Celligoi, A. (2012). Avaliação preliminar da qualidade da água subterrânea no município de Ibiporã-PR. Revista de Estudos Ambientais, 14(2), 39-48. http://dx.doi. org/10.7867/1983-1501.2012v14n2p39-48

Cunha, P. R. C., Melo, J. H. G., Silva, O. B. (2007). Bacia do Amazonas. Boletim de Geociências da Petrobras, 15(2), 227-251.

Dall'olio, A., Salati, E., Azevedo, C. T., Matsui, E. (1979). Modelo de fracionamento isotópico da água na bacia
Amazônica (Primeira aproximação). Acta Amazônica, 9(4), 675-687. http://dx.doi.org/10.1590/1809-43921979094675

Davis, S. N., Moysey, S., Cecil, L. D. W., Zreda, M. (2003). Chlorine-36 in groundwater of the United States: empirical data. Hydrogeology Journal, 11(2), 217-227. https://doi. org/10.1007/s10040-002-0232-6

Davis, S. N., Whittemore, D. O., Martin, J. F. (1998). Uses of Chloride/Bromide Ratios in Studies of Potable Water. Groundwater, 36(2),338-350. https://doi.org/10.1111/j.1745-6584.1998.tb01099.x

Dino, R., Silva, O. B., Abrahão, D. (1999). Caracterização palinológica e estratigráfica de estratos cretáceos da Formação Alter do Chão, Bacia do Amazonas. V Simpósio sobre o Cretáceo do Brasil, 557-565. Rio Claro: UNESP.

Feitosa, F. A. C., Manoel Filho, J., Feitosa, E. C., Demetrio, J. G. A. (2008). Hidrogeologia: Conceitos e Aplicações. $3^{\mathrm{a}}$ ed. Rio de Janeiro: CPRM - LABHID.

Food and Agricultural Organization - FAO. (2003). Review of world water resources by country. Water Report 23. Land and Water Development Division. Roma: FAO. 110 p.

Galvão, P. H. F., Demétrio, J. G. A., Souza, E. L., Pinheiro, C. S. S., Baessa, M. P. M. (2012). Hidrogeologia e geometria dos aquíferos das formações cretáceas Içá e Solimões, Bacia Paleozoica do Solimões, na região de Urucu, Amazonas. Revista Brasileira de Geociências, 42(1), 142-153. http:// dx.doi.org/10.5327/Z0375-75362012000500012

Gonçales, S. C. B., Miranda, J. S. N. (2014). Caracterização da qualidade das águas subterrâneas do aquífero Alter do Chão, estudos de caso das estações da rede de monitoramento de águas subterrâneas (RIMAS - CPRM) no município de Manaus-AM. Anais do XVIII Congresso Brasileiro de Águas Subterrâneas. Belo Horizonte: ABAS. Disponível em: $<$ https://aguassubterraneas.abas.org/asubterraneas/article/ view/28381/18476>. Acesso em: 25 nov. 2016.

Han, D. N., Liang, X., Jin, M. G., Currell, M. J., Song, X. F., Liu, C. M. (2010). Evolution of groundwater hydrochemical characteristic and mixing behavior in the Daying and Qicum geothermal systems, Xinzhou Basin. Journal of Volcanology and Geothermal Research, 189(1), 92-104. http://dx.doi. org/10.1016/j.jvolgeores.2009.10.011

Hatfield, R., Patrick, C. (2016). Radiocarbon dating of groundwater: practical applications. Beta Analytical Inc. Disponível em: <http://www.radiocarbon.com/PDF/ Groundwater\%20Radiocarbon\%20Dating\%20Practical\%20 Applications.pdf>. Acesso em: 25 nov. 2016. 
Hofmann, H., Cartwright, I. (2013). Using hydrogeochemistry to understand inter-aquifer mixing in the on-shore part of the Gippsland Basin, southeast Australia. Applied Geochemistry, 33(1), 84-103. http://dx.doi.org/10.1016/j. apgeochem.2013.02.004

Honório, B. A. D. (2007). Água da chuva na Amazônia Ocidental: química e composição isotópica. Dissertação (Mestrado). Manaus: Programa de Pós-Graduação em Geociências, Universidade Federal do Amazonas - UFAM.

Horbe, A. M. C., Vieira, L. C., Nogueira, A. C. R. (2006). Geoquímica de camadas vermelhas bioturbadas da Formação Alter do Chão, Cretáceo da bacia do Amazonas. Revista Brasileira de Geociências, 36(3), 396-402.

Instituto Brasileiro de Geografia e Estatística-IBGE. (2011). Base Cartográfica Digital Contínua da Amazônia Legal $B C A L$. Escala 1:100.000. Rio de Janeiro: IBGE. Disponível em: <www.ibge.gov.br>. Acesso em: 25 nov. 2016.

International Atomic Energy Agency - IAEA. (2013). Isotope methods for dating old groundwater. Viena: IAEA.

International Atomic Energy Agency - IAEA, World Meteorological Organization - WMO (2017). Global Network of Isotopes in Precipitation (GNIP Database). Global Network of Isotopes in Rivers (GNIR Database). Dísponível em: <http://www.iaea.org/water>. Acesso em: 25 nov. 2016.

Kehew, A. E. (2001). Applied chemical hydrogeology. Nova Jersey: Prentice Hall.

Li, X., Zhang, L., Hou, X. (2008). Use of hydrogeochemistry and environmental isotopes for evaluation of groundwater in Qingshuihe Basin, northwestern China. Hydrogeology Journal, 16(1), 335-348. https://doi.org/10.1007/ s10040-007-0269-7

Loáiciga, H. (2004). Residence time, groundwater age, and solute output in steady-state groundwater systems. Advances in Water Resources, 27(1), 681-688. https://doi.org/10.1016/j. advwatres.2004.05.004

Mazor, E. (1991). Chemical end isotopic groundwater hydrology: the applied approach. Londres: Marcel Bekker. 413 p.

Mendes, A. C. (2010). Litofácies e minerais pesados da Formação Alter do Chão (Cretáceo), região de Óbidos-PA, parte central da bacia do Amazonas. Dissertação (Mestrado). Belém: Programa de Pós-Graduação em
Geologia e Geoquímica, Universidade Federal do Pará - UFPA.

Miranda, M. J. O., Silva, M. L., Bringel, S. R. B. (2011). Dinâmica Hidrogeoquímica das Águas Subterrâneas do Município de Novo Airão-AM. XX Jornada de Iniciação Cientifica PIBIC INPA-CNPq/FAPEAM. Manaus: INPA.

Motta, M. B. (2008). Proveniência da Formação Içá e de sedimentos do Rio Solimões, entre os municipios de Tefé e Manacapuru-Amazonas. Dissertação (Mestrado). Manaus: Programa de Pós-Graduação em Geociências - UFAM.

Mullaney, J. R., Lorenz, D. L., Arntson, A. D. (2009). Chloride in groundwater and surface water in areas underlain by the glacial aquifer system, northern United States. Reston: U.S. Geological Survey Scientific Investigations Report, 41 p.

Nwankwoala H. O., Udom G. J. (2011). Hydrochemical Facies and Ionic Ratios of Groundwater in Port Harcourt, Southern Nigeria. Research Journal of Chemical Sciences, 1(3), 87-101.

Organização do Tratado de Cooperação Amazônica OTCA (2006). Visão estratégica para o planejamento e gerenciamento dos recursos hidricos e do solo, frente às mudanças climáticas e para o desenvolvimento sustentável da bacia hidrográfica do Rio Amazonas. Projeto GEF Amazonas - OTCA/PNUMA/OEA. Relatório final. Brasília: OTCA.

Parkhurst, D. L., Appelo, C. A. J. (2013). Description of input and examples for PHREEQC version 3--A computer program for speciation, batch- reaction, one-dimensional transport, and inverse geochemical calculations. U.S. Geological Survey Techniques and Methods, v. 6. 497 p. Cap. A43. Disponível em: <http://pubs.usgs.gov/tm/06/ a43>. Acesso em: 13 mar. 2017.

Pearson, F. J. (1965) Use of C-13/C-12 ratios to correct radiocarbon ages of material initially diluted by limestone. In: Proceedings of the $6^{\text {th }}$ International Conference on Radiocarbon and Tritium Dating, 357. Washington, D.C.: Pulman.

Petróleo Brasileiro - Petrobras. (2009). Mineralogia total $e$ de argilominerais de amostras de furos geológicos nas Formações Solimões e Alter do Chão, Bacia do Solimões. Relatório Interno. Brasil: Gerência de Sedimentologia e Petrologia, CENPES.

Piper, A. M. (1944) A graphic procedure in the geochemical interpretation of water-analysis. Transactions American Geophysical union, 25, 914-928. https://doi.org/10.1029/ TR025i006p00914 
Price, L. I. (1960). Dentes de Theropoda num testemunho de sonda no Estado do Amazonas. Anais da Academia Brasileira de Ciências, 32(1), 79-84.

Projeto Radar da Amazônia - RADAMBRASIL. (1978). Folha SA.20 Manaus: geologia; geomorfologia, pedologia, vegetação, uso potencial da terra. Rio de Janeiro: DNPM. p. $17-165$.

Rocha, L. C., Horbe, A. M. C. (2006). Contaminação provocada por um depósito de lixo no aquífero Alter do Chão em Manaus - AM. Acta Amazônica, 36(3), 307-312. http://dx.doi.org/10.1590/S0044-59672006000300003

Rosário, F. F. (2011). O Sistema Aquífero Cretáceo Multicamada Tikuna: Subunidade de Sistema Aquifero Amazonas. Tese (Doutorado). Rio de Janeiro: Programa de Pós-Graduação em Geologia, Universidade Federal do Rio de Janeiro - UFRJ.

Rosário, F. F., Custodio, E., Silva Jr., G. C. (2016). Hydrogeology of the Western Amazon Aquifer System (WAAS). Journal of South American Earth Sciences, 72(1), 375-386. https://doi.org/10.1016/j. jsames.2016.10.004

Rossetti, D. F., Toledo, P. M., Góes, A. M. (2005). New geological framework for Western Amazônia (Brazil) and implications for biogeography and evolution. Quaternary Research, 63(1), 78-89. https://doi.org/10.1016/j. yqres.2004.10.001

Salati, E., Dall'olio A., Matsui, E., Gat, J. R. (1979). Recycling of water in the Amazon basin: an isotopic study. Water Resources Research, 15(5), 1250-1258. https://doi. org/10.1029/WR015i005p01250

Santos, J. O. S. (1978). Magmatismo Básico-Alcalino no Proterozoico Superior da Plataforma Amazônica. XXX Congresso Brasileiro de Geologia, 3, 1309-1322. Recife: SBG.

Scomazzon, A. K. (2004). Estudo de Conodontes em carbonatos marinhos do Grupo Tapajós, Pensilvaniano Inferior a Médio da Bacia do Amazonas com aplicação de isótopos de Sr e Nd neste intervalo. Tese (Doutorado). Porto Alegre: Universidade Federal do Rio Grande do Sul - UFRGS.

Silva, A. J. P., Lopes, R. C., Vasconcelos, A. M., Bahia, R. B. C. (2003). Bacias Sedimentares Paleozoicas e MesoCenozoicas Interiores. In: L. A. Bizzi, C. Schobbenhaus, R. M. Vidotti, J. H. Gonçalves (Eds.) Geologia, tectônica e recursos minerais do Brasil: texto, mapas \& SIG. Brasília: CPRM - Serviço Geológico do Brasil.

Silva, M. L. (2005). Estudo hidroquímico e dos isótopos de urânio nas águas subterrâneas em cidades do estado do Amazonas. Tese (Doutorado). Rio Claro: Instituto de Geociências e Ciências Exatas, Universidade Estadual Paulista "Júlio de Mesquita Filho" - UNESP.

Silva, M. L., Bonotto, D. M. (2006) Hidroquímica elementar e dos isótopos de urânio em águas subterrâneas da Formação Alter do Chão, Manaus (AM). Revista Brasileira de Geociências, 36(3), 437-448.

Silva, M. L., Silva, M. S. R. (2007). Hidrogeoquímica das águas subterrâneas da cidade de Iranduba (AM), Brasil. Caminhos de Geografia, 8(22), 87-96.

Silva Jr., G. C, Cristo, V. N. (2014). O uso de ferramentas geoquímicas na identificação do comportamento da cunha salina do aquífero costeiro do Distrito de Itaipuaçu, Maricá - RJ. Águas Subterrâneas, 28(1), 80-94. https://doi. org/10.14295/ras.v28i1.27403

Silveira, R. R., Souza, P. A. (2015). Palinologia (grãos de pólen de Angiospermas) das Formações Solimões e Içá (Bacia do Solimões), nas regiões de Coari e Alto Solimões, Amazonas. Revista Brasileira de Paleontologia, 18(3), 455-474. http://dx.doi.org/10.4072/rbp.2015.3.10

Sioli, H. (1975). Amazon Tributaries and Drainage Basins. In: A. D. Hasler (Ed.), Coupling of Land and Water Systems. Berlim: Springer-Verlag. p. 199-213.

Soares, E. A. A., Wahnfried, I., Dino, R. (2016). Estratigrafia de subsuperfície da sequência sedimentar cretácea-neógena das regiões de Manaus e Itacoatiara, Amazônia Central. Geologia USP. Série Cientifica, 16(1), 22-41. http://dx.doi. org/10.11606/issn.2316-9095.v16ilp23-41

Souza, E. L., Galvão, P., Almeida, R., Pinheiro, C., Baessa, M., Cabral, M. (2015). Stable Isotopes Studies in the Urucu Oil Province, Amazon Region, Brazil. Journal of Water Resource and Protection, 7, 131-142. http://dx.doi. org/10.4236/jwarp.2015.73011

Souza, E. L. S., Galvão, P. H. F., Pinheiro, C. S. S., Baessa, M. P. M., Demétrio, J. G. A., Brito, W. R. R. (2013). Síntese da hidrogeologia nas bacias sedimentares do Amazonas e do Solimões: Sistemas Aquíferos Içá-Solimões e Alter do Chão. Geologia USP. Série Científica, 13(1), 107-117. http://dx.doi.org/10.5327/ Z1519-874X2013000100007 
Souza, L. S. B. (2005). Mapeamento de aquiferos na cidade de Manaus (AM) utilizando perfilagem geofisica de poço e sondagem elétrica vertical. Dissertação (Mestrado). Belém: Curso de Pós-Graduação em Geofísica, Universidade Federal do Pará - UFPA.

Stuiver, M., Reimer, P. J., Reimer, R. W. (2018). Software Calib 7.1. Disponível em: <http://calib.org>. Acesso em: 5 jan. 2018.

Tancredi, A. C. F. N. S. (1996). Recursos hídricos subterrâneos de Santarém: fundamentos para uso e proteção. Tese (Doutorado). Belém: Curso de Pós-Graduação em Geologia e Geoquímica, Universidade Federal do Pará - UFPA.
Vasconcelos, T. A. (2006). Estudos físico-químicos e microbiológicos de águas de poços tubulares da cidade de Manaus. Dissertação (Mestrado). Manaus: Programa de Pós-Graduação em Geociências, Universidade Federal do Amazonas - UFAM.

Ward, J. V. (1985). Thermal characteristics of running waters. Hydrobiologia, 125(1), 31-46. https://doi.org/10.1007/ BF00045924

Zhu, C., Anderson, G. (2002). Environmental Applications of Geochemical Modeling. Cambridge: University Press. 